\title{
|ESTIMANDO LOS EFECTOS DE LA INMIGRACIÓN VENEZOLANA EN COLOMBIA MEDIANTE UN MODELO DE EQUILIBRIO GENERAL COMPUTADO ${ }^{1}$
}

\author{
PABLO DE LA VEGA ${ }^{2}$
}

\section{RESUMEN}

Se utiliza un modelo de Equilibrio General Computado (CGE) para analizar los efectos de la masiva inmigración venezolana en Colombia en los últimos años. Mediante simulaciones, se comparan diferentes escenarios asociados al shock migratorio, incluyendo intervenciones de política y ayuda internacional. Se encuentra que, a pesar de la caída en los salarios reales y el aumento del desempleo, la migración tiende a aumentar los niveles de ingreso, actividad y bienestar. Estos resultados son consistentes con la evidencia previa y permiten obtener intuiciones básicas y órdenes de magnitud de los efectos.

Palabras clave: Modelo de Equilibrio General, Migración, Estructura salarial, Colombia, Venezuela

\section{ESTIMATING THE EFFECTS OF VENEZUELAN IMMIGRATION IN COLOMBIA THROUGH A GENERAL COMPUTED EQUILIBRIUM MODEL}

\begin{abstract}
A Computable General Equilibrium (CGE) model is used to analyze the effects of the massive Venezuelan immigration in Colombia in recent years. Through simulations, different scenarios associated with the migratory shock are compared, including policy interventions and international aid. It is found that, despite the fall in real wages and the increase in unemployment, migration tends to increase levels of income, activity and welfare. These results are consistent with previous evidence and allow obtaining basic insights and orders of magnitude of the effects.

Keywords: General Equilibrium Model, Migration, Wage Structure, Colombia, Venezuela.
\end{abstract}

Clasificación JEL: C68, F22, J31, O24.

Recibido:23/12/2019. Aceptado:29/09/2020

\footnotetext{
${ }^{1}$ Agradezco especialmente a Martín Cicowiez y a Jorge Carrera por su valiosa guía y apoyo en el proceso de elaboración de este trabajo, y a Gonzalo Nocetti Perez, quien leyó una versión borrador de este artículo. Además, agradezco a dos referís anónimos, cuyos comentarios y recomendaciones enriquecieron sustancialmente este trabajo. Finalmente, agradezco el financiamiento provisto por la Universidad Nacional de La Plata. Cualquier error es de mi entera responsabilidad.

${ }^{2}$ Departamento de Economía, Facultad de Ciencias Económicas, Universidad Nacional de La Plata (UNLP), Calle 6 \#777, La Plata, Argentina (e-mail: delavegapc@gmail.com).
} 


\section{Introducción}

Durante décadas, Venezuela ha sido receptor de migrantes de toda Latinoamérica, sin embargo, esto se revirtió en los últimos años. La caída de los precios de los commodities expuso la fragilidad de un país altamente dependiente de las exportaciones de petróleo y metales preciosos, y con un severo mal manejo de política macroeconómica (Vera, 2015). El resultado es una profunda crisis económica, social y humanitaria, con estanflación, escasez de alimentos y bienes básicos, y niveles inusitados de pobreza (Banco Mundial, 2018; Human Rights Watch, 2019).

Representando el éxodo migratorio más grande en la historia de Latinoamérica, desde 2014, cerca de cuatro millones de personas abandonaron Venezuela dirigiéndose principalmente a países vecinos (UNHCR, 2019). En particular, Colombia es el mayor receptor de migrantes venezolanos, ya que estos países no solo comparten $2,218 \mathrm{~km}$. de frontera, sino también una larga historia comercial, cultural y migratoria (Banco Mundial, 2018; Ruiz Mirabal, 2018).

El flujo de venezolanos hacia Colombia se aceleró desde 2015, pero en mayor medida desde agosto de 2016, cuando se levantó el bloqueo de las fronteras luego de estar cerradas durante un año (Gedan, 2017). Actualmente, se estima que dos millones de venezolanos han ingresado a Colombia, tanto por canales regulares como irregulares, y el $80 \%$ planea quedarse de forma permanente (Selee et al., 2019; Migración Colombia, 2020)ํ․ Según el Banco Mundial (2018), si bien la mayor parte de esta migración obedece a razones económicas, el fenómeno comienza a compartir características con otras crisis de refugiados: un influjo abrupto y una alta proporción de personas en condiciones de vulnerabilidad socioeconómica.

En consecuencia, han emergido serias preocupaciones acerca del impacto de tamaña migración sobre la economía colombiana. Al respecto, en este paper se sigue un enfoque diferente al de la extensa literatura que analiza los impactos de la inmigración en las economías receptoras a través de estimaciones de forma reducida de salarios y empleo. A pesar de que dichos trabajos proveen evidencia útil acerca de los efectos directos en el mercado laboral, no tienen en cuenta la multiplicidad de efectos de equilibrio general.

En este sentido, en el presente trabajo se estudia la dirección y la magnitud de los efectos del shock migratorio en la economía colombiana mediante simulaciones en un modelo de equilibrio general computado (CGE; del inglés, Computable General Equilibrium), haciendo foco en la caracterización de los inmigrantes en función de su nivel de calificación. A diferencia de otros fenómenos migratorios masivos, este tiene la particularidad de que existe una importante homogeneidad cultural entre las poblaciones de origen y de destino. Entonces, es razonable suponer sustitución perfecta entre estos grupos, mientras se divide a los trabajadores en categorías imperfectamente sustitutas, por su nivel de calificación.

Diferentes escenarios contrafácticos asociados al shock migratorio son considerados, evaluando impactos sectoriales y a nivel agregado. Además del shock de oferta laboral, se simulan cambios en la cuenta de remesas de la balanza de pagos, intervenciones de política y ayuda internacional. El modelo es calibrado mediante una matriz de contabilidad social (SAM; del inglés, Social Accounting Matrix) actualizada (Cicowiez, 2019) y encuestas de hogares.

\footnotetext{
${ }^{3}$ Al igual que Perú, Colombia otorgó a los venezolanos permisos de residencia temporaria, permitiéndoles acceder a derechos sociales básicos y poder trabajar (Banco Mundial, 2018).
} 
Los principales resultados son los siguientes. A pesar de la caída en los salarios reales y el aumento del desempleo, la migración tiende a aumentar el nivel general de ingresos, la actividad económica, y la recaudación impositiva. El mayor nivel de ahorro agregado financia un incremento en la inversión. El bienestar, medido por la variación equivalente, aumenta. El aumento de gasto público simulado tiende a favorecer en mayor medida al segmento de trabajadores calificados, ya que expande la demanda de sectores intensivos en dicho factor. Mientras tanto, la ayuda internacional relaja la restricción presupuestaria de los hogares, impulsando el consumo privado. Las ganancias agregadas y sectoriales son menores en un escenario donde los migrantes no logran acreditar sus estudios y todo el influjo se incorpora al segmento no calificado del mercado laboral.

Estos hallazgos son consistentes con la evidencia existente sobre los impactos de flujos migratorios masivos y con aquellos trabajos analizando la migración de venezolanos hacia Colombia. Si bien dependen fuertemente de la modelización y los datos utilizados, los resultados pueden ser interpretados como un indicador cualitativo de la dirección y la magnitud de los efectos.

El resto del trabajo se organiza como sigue. En la siguiente sección se establece un marco teórico de referencia en base a la literatura previa. En la Sección 3 se presentan hechos estilizados asociados al flujo migratorio venezolano y al contexto macroeconómico colombiano. En la Sección 4 se describe el modelo de CGE que será utilizado, y en la sección 5 se lo calibra. En la Sección 6 se definen las simulaciones y se muestran los resultados. Finalmente, en la Sección 7 se concluye.

\section{Marco teórico}

\section{II.1. Impactos esperados de los flujos migratorios}

El análisis de los efectos de grandes influjos migratorios ha sido extensivamente abordado en la literatura, principalmente motivado por las predicciones teóricas acerca de los impactos negativos en los mercados laborales. Sin embargo, dicho shock genera una multiplicidad de efectos directos e indirectos, y las consecuencias últimas dependen de varias condiciones en la economía receptora.

En el caso de una economía cerrada, el modelo canónico del mercado laboral predice un efecto directo asociado al aumento en la oferta, de modo que se evidenciaría una caída en la remuneración de los factores, a menos que su demanda sea completamente elástica. Esto induce dos efectos en las decisiones de producción. Por un lado, un efecto sustitución, de modo que disminuye la demanda relativa de aquellos factores que ahora son relativamente más caros (manteniendo fijo el nivel de producción). Por otro lado, el abaratamiento de costos genera un efecto escala que expande la producción y el empleo de todos los factores. Si este último efecto predomina, los factores son complementos brutos, mientras que, si ocurre lo contrario, son sustitutos brutos. En este sentido, resulta crucial la manera en que se caracteriza al flujo migratorio y las dimensiones en las que se lo compara con la fuerza laboral del país receptor. En un escenario de migración forzosa, además, la caída de los salarios reales podría inducir a que los nativos abandonen el mercado, dado que su salario de reserva tiende a ser mayor que el de los migrantes. Por el contrario, en presencia de rigideces salariales, el shock de oferta resultaría en un mayor desempleo. 
En una economía abierta, las cosas pueden ser diferentes. En modelos de tipo HeckscherOhlin, el "efecto Rybczynski" señala que un cambio en las dotaciones factoriales induce una expansión de la frontera de posibilidades de producción de forma sesgada hacia la producción de aquellos sectores que usan intensivamente el factor cuya dotación relativa aumentó. Entonces, si el shock no es lo suficientemente grande para modificar el patrón de especialización, la remuneración relativa de los factores no debería cambiar, ya que depende del precio de los bienes que se comercian (Krugman et al., 2018). Sin embargo, el ajuste de la estructura productiva se torna menos factible en presencia de, por ejemplo, factores productivos inmóviles, sectores no transables, o estructuras productivas poco diversificadas (Venables, 1999, Dustman et al., 2005).

A pesar de la prolífera literatura empírica desde el trabajo seminal de Card (1990), no existe un consenso sobre la magnitud y la dirección de los impactos de un abrupto influjo de migrantes sobre el mercado laboral. Para una revisión extensiva ver, entre otros, Longhi et al. (2005), Ruiz et al. (2013), Maystadt et al. (2019). Inicialmente, esta literatura distinguía entre nativos y migrantes en base a diferencias culturales y/o de idioma. Sin embargo, trabajos más recientes han optado por dividir a los trabajadores entre grupos imperfectamente sustitutos, por ejemplo, por educación y experiencia, mientras asumen sustitución perfecta entre nativos y migrantes (Borjas, 2003). En términos generales, los efectos negativos sobre el mercado laboral tienden a ser marginales (Blanchflower et al., 2007; Dustmann et al, 2008; Lemos y Portes, 2008; Kerr y Kerr, 2011).

En el marco de esta literatura, varios autores han estimado el impacto de la migración venezolana en Colombia. Mediante las metodologías de diferencias en diferencias y de control sintético, Peñaloza Pacheco (2019) estima el efecto de corto plazo del éxodo migratorio sobre el salario real en las regiones fronterizas más afectadas. El autor encuentra que un incremento del $10-15 \%$ de la fuerza laboral induce una caída promedio en el salario real de entre $6 \%$ y $9 \%$, siendo mayor para los hombres y para aquellos trabajadores de baja calificación y en el sector informal. Caruso et al. (2019) obtienen resultados similares, pero mediante el uso de variables instrumentales.

Además de las consecuencias sobre el mercado laboral, la literatura también identifica impactos sobre el sistema de seguridad social, el nivel de precios, el crecimiento económico y las cuentas públicas. Por ejemplo, la migración puede mitigar la desaceleración del crecimiento de la fuerza laboral que es consecuencia del envejecimiento poblacional (Sanchez-Martinez et al., 2013; OECD e ILO, 2018). Además, según Kerr y Kerr (2016), los migrantes suelen tener un espíritu emprendedor, que se cristaliza en la creación de nuevos negocios e incrementos de empleo y productividad. En relación a los efectos sobre los precios, el efecto esperado es ambiguo, y depende en gran medida de cómo sean afectadas la oferta y la demanda (Blanchflower et al., 2007).

Respecto a las finanzas públicas, los impactos dependen de: i) las transferencias del gobierno a los hogares, ii) las respuestas de política que el país receptor decida implementar, y, iii) el tipo de migración. Por ejemplo, los migrantes con alta calificación que se inserten en el mercado laboral con un buen salario, son menos dependientes de programas sociales y pueden compensar los gastos de otros migrantes (en trasferencias y servicios públicos) contribuyendo a la recaudación impositiva (Gott et al., 2005). Por otro lado, se evidenciaría un incremento del gasto público en caso de que el país receptor responda con incrementos en partidas presupuestarias relacionadas a servicios de salud, educación, vivienda, etc. Finalmente, los ingresos fiscales 
podrían crecer de la mano de aumentos en los niveles de ingreso y de actividad (Dustmann et al., 2010).

\section{II.2. Modelos de CGE sobre migración}

La multiplicidad de efectos directos e indirectos asociados a los influjos migratorios hace evidente la necesidad de utilizar modelos de equilibrio general para analizarlos (Ottaviano y Peri, 2012). En efecto, a lo largo de las últimas décadas, los modelos de CGE han sido extensivamente utilizados para el análisis empírico en diversos temas, incluyendo shocks migratorios (Devarajan y Robinson, 2005). Un modelo de CGE detalla el comportamiento de los agentes económicos según los principios de la optimización e integra la conducta de los agentes de forma sistemática. Así, provee una estructura consistente y micro-fundamentada que permite evaluar los efectos económicos directos e indirectos de determinado shock (Shoven y Whalley, 1984).

Algunas aplicaciones de este tipo de modelos en temas migratorios se comentan a continuación. Sussangkarn (1996) utiliza un modelo de CGE para analizar el impacto de la inmigración en Tailandia. Distingue entre trabajadores nativos calificados y no calificados, pero solo considera a los migrantes de baja calificación en el análisis. Encuentra que el producto se expande, pero trabajadores de baja calificación son afectados negativamente. Brucker y Koglhaas (2004) utilizan un modelo de CGE multi-regional para evaluar los efectos de la migración desde Europa a Alemania, modelizando mercados laborales con rigideces salariales y tres tipos de trabajo según su nivel de calificación. Los resultados sugieren que, en el caso de Alemania, importa más la estructura de capacidades de la población que el tamaño del flujo, ya que algunos segmentos del mercado laboral son más rígidos que otros. Más recientemente, Pouliakas et al. (2014) utilizan un modelo de CGE regional para analizar los efectos de la inmigración en tres regiones pequeñas de Europa. Evalúan el impacto de diferentes tamaños de los flujos y de diversos tipos de calificación. Encuentran que las regiones de origen sufren de la pérdida de trabajadores calificados, mientras que las regiones receptoras evidencian un aumento en la desigualdad ante la llegada de trabajadores no calificados.

En relación a eventos de migración forzosa, Taylor et al. (2016), utilizan un modelo de equilibrio general para tres asentamientos de refugiados y el área que los rodea en Ruanda. Los resultados del análisis sugieren que, debido al aumento de la oferta laboral y de la demanda de consumo impulsada por la ayuda internacional, los refugiados inducen incrementos en los ingresos de los hogares locales. Filipski et al. (2019) evalúan las consecuencias de la migración forzosa desde Myanmar hacia Bangladesh utilizando un modelo estático a nivel sub-nacional. Simulan diferentes escenarios, incluyendo varias opciones para el tamaño del mercado receptor y para la provisión de ayuda internacional. Encuentran que, si un gran número de migrantes entra a un mercado pequeño, induciría una caída en los salarios de 30\%, mientras que solo de $4 \%$ en uno más grande.

\section{II.3. Modelos de CGE en Colombia}

El uso de modelos de CGE para el análisis económico en Colombia tiene una larga tradición. Revisiones bibliográficas extensivas pueden ser encontradas, por ejemplo, en López, et al. (1994), Hernández (2013), Pinzón Piedrahita (2015), Escobar-Espinoza et al. (2017), y Suescún 
y Steiner (2017). A los fines de nuestro trabajo, es relevante poner en perspectiva la forma en que suele modelizarse el lado de la producción y el mercado laboral en dicha literatura.

Existe una amplia heterogeneidad en la forma en que se modela el lado de la producción. Ciertos trabajos utilizan formas funcionales de tipo Cobb-Douglas (Atuesta et al. 2013; Suescún y Steiner, 2017). Similarmente, otros modelizan funciones CES que combinan trabajo, tierra y capital, con una elasticidad de sustitución unitaria (Light y Rutherford, 2002 y 2003; Vaughan Caro, 2005). Por otro lado, varios trabajos asumen una función CES que combina un compuesto de diferentes tipos de trabajo y capital (Perdomo, 2008; Botero et al., 2011; Correa Giraldo, et al. 2018).

En cuanto a la modelización del mercado laboral, Bussolo, et al. (1998) construyen el modelo COGEM, que incluye segmentación en el mercado laboral e implementación de salario mínimo. Light y Rutherford (2002) desarrollan el modelo MEGATAX para la evaluación de políticas fiscales, que incluye algunas especificaciones del mercado laboral con ajuste de precios, desempleo e informalidad. Bussolo y Lay (2003), modelizan un mercado laboral formal con rigideces a través de una curva de salarios, mientras el mercado informal ajusta residualmente.

La única referencia que hemos encontrado sobre análisis de la migración desde Venezuela a Colombia mediante un modelo de CGE es Banco Mundial (2018), donde se utiliza un modelo desarrollado por el Departamento Nacional de Planeación (DNP) para evaluar impactos a nivel de agregados macroeconómicos. El modelo, calibrado con una SAM de 2009, es dinámico recursivo, miope; con un único hogar. El trabajo es desagregado en calificado y no calificado, y el mercado laboral segmentado en formal e informal. Consideran cuatro escenarios respecto al aumento de la fuerza laboral $(0.5 ; 1 ; 1.5 ;$ y 2 millones), repartido 30\% en 2016 y $70 \%$ en 2017. Asumen que todos los migrantes ofrecen trabajo informal no calificado, por las dificultades en acreditar sus diplomas. Esto último es curioso ya que en el trabajo afirman que, el mayor impacto de la migración en el mercado laboral ha sido la pérdida de empleos formales debido a que la población migrante cuenta con un nivel mayor de educación y competencias en comparación con la población de áreas receptoras (Banco Mundial, 2018; pág. 22). Encuentran que el shock genera crecimiento económico en el mediano plazo, debido a aumentos en inversión y consumo.

\section{Hechos estilizados ${ }^{4}$}

En esta sección se caracteriza el flujo migratorio de venezolanos a Colombia y el contexto macroeconómico colombiano en el que ocurre. Al respecto, mediante el módulo de migración de la Gran Encuesta Integrada de Hogares (GEIH) del Departamento Administrativo Nacional de Estadística (DANE), es posible analizar la evolución reciente de los flujos migratorios hacia Colombia distinguiendo aquellos individuos que vivían en otro país hace 12 meses y 5 años. A lo largo de esta sección, se define migrante a aquella persona que vivía en otro país hace 1 año.

Como se muestra en la Tabla A.1, el número de inmigrantes se aceleró fuertemente a partir de 2016 y, a pesar de que Colombia recibe migrantes de varios países, la proporción de migrantes desde Venezuela se incrementó desde 38.4\% (25,913) en 2014, a 90.74\% $(767,587)$ en 2019. Complementariamente, en la Figura A1 se desagrega el flujo de inmigrantes desde Venezuela por nacionalidad. Por un lado, se observa un número sostenido de colombianos regresando a su país y, por otro lado, un gran y creciente flujo de venezolanos ingresando a Colombia.

\footnotetext{
${ }^{4}$ Para facilitar la exposición, las tablas y figuras de esta sección se reportan en el Apéndice A.
} 
A partir de lo discutido en el marco teórico se desprende que, a la hora de evaluar los impactos sobre la economía receptora, es crucial la forma en que se caracteriza al flujo migratorio y se lo compara con la población residente. Entonces, para dilucidar en qué medida y de qué modo el shock migratorio afecta la composición de la fuerza laboral, a continuación, se caracteriza a los migrantes y se los compara con los residentes en función de los niveles de calificación y participación en el mercado laboral. El análisis se restringe a la población en edad de trabajar (PET; personas de entre 15 y 64 años de edad), y se define no calificado (semi-calificados) a aquel individuo cuyo máximo nivel educativo alcanzado es menor que secundaria (superior) completa, mientras calificado es aquel con educación superior completa.

En la Tabla A.2, se muestra la evolución de los migrantes venezolanos, por nivel de calificación. A su vez, se reporta el porcentaje de cada categoría que participa activamente en el mercado laboral, es decir, que pertenece a la Población Económicamente Activa (PEA). Para las tres categorías de calificación, los niveles de migrantes se incrementan fuertemente a partir de 2016, mientras que las tasas de actividad son altas y mayores para el período 2016-2019. Adicionalmente, en la Tabla A.3, se reporta la desagregación por nivel de calificación de los venezolanos migrantes y de los colombianos residentes, ambos pertenecientes a la PEA. Comparativamente, se evidencia que los migrantes venezolanos tienen una proporción algo mayor de trabajadores activos semi-calificados, mientras lo contrario ocurre para los segmentos de no calificados y calificados.

A los fines de evaluar si existen diferencias estadísticamente significativas en niveles de actividad y calificación entre residentes y migrantes venezolanos, en la Tabla A.4 se reportan simples diferencias de medias no condicionadas. La presencia de migrantes en la fuerza laboral es significativamente mayor que para los nativos, y dicha diferencia es mayor para el sub-período 2016-2019. Esta diferencia es esperable dado el mayor costo de oportunidad que enfrentan los migrantes. Dentro de la PEA, la población de migrantes venezolanos tiene una menor proporción de no calificados y de calificados, mientras tiene una mayor proporción de semi-calificados, siendo todas estas diferencias estadísticamente significativas.

Finalmente, para dimensionar la inmigración de venezolanos, en la Tabla A.5 se presenta la evolución en niveles de la PEA y de los migrantes venezolanos. Entre 2017 y 2019, 794,214 migrantes venezolanos se sumaron activamente al mercado laboral colombiano, cifra que representa un $3.45 \%$ de la PEA total de Colombia de 2016. Desagregando este flujo por nivel de calificación, en promedio, el $33.63 \%$ es no calificado, el $54.17 \%$ es semi-calificado, y el restante $12.19 \%$ es calificado. Al final de la tabla, se reporta el porcentaje que representa el influjo respecto a la PEA con igual nivel de calificación en 2016. Para las tres categorías, la inmigración es un shock importante, pero en mayor medida para el segmento de semi-calificados (4.34\%).

Por otro lado, es importante tener en cuenta que este influjo ha ocurrido en una coyuntura de magro desempeño económico en Colombia (FeDesarrollo, 2018). Al respecto, en la Figura A.2 se muestra la evolución del PBI de Colombia durante los últimos años. A pesar de que el nivel de ingreso real creció durante todo el período, la tasa de crecimiento se ha ido desacelerando. Como se muestra en la Tabla A.6, esto se reflejó en el mercado laboral, cuyas tasas de desempleo han evidenciado una tendencia creciente, luego de un salto discreto en 2016. Mediante un ejercicio análogo al de la Tabla A.4, al final de la Tabla A.6 se comparan las tasas de desempleo entre la población de venezolanos (migrantes y no migrantes) y los nativos. Se evidencia que los primeros tienen relativamente mayores probabilidades de estar desempleados. 
Una característica distintiva de este shock migratorio es que Venezuela y Colombia comparten una larga historia comercial, cultural y migratoria (Ruiz Mirabal, 2018; Banco Mundial, 2018), de modo que existe una importante homogeneidad cultural entre las poblaciones de origen y de destino. Las diferencias recién discutidas son esperables en cualquier proceso migratorio masivo. Entonces, es razonable asumir sustitución perfecta entre estos grupos, mientras se divide a los trabajadores en categorías imperfectamente sustitutas, por su nivel de calificación.

Finalmente, vale aclarar que la migración venezolana no se ha distribuido de manera homogénea en Colombia. Sin embargo, según Caruso et al. (2019), a pesar de que los inmigrantes se concentran en los grandes focos económicos del noreste, dado el tamaño de dichas ciudades, las presiones que esos flujos migratorios podrían generar en los mercados y servicios públicos locales probablemente sean pequeñas ${ }^{5}$. Además, fuentes oficiales advierten que se comienza a evidenciar una redistribución de la población venezolana en el país (Migración Colombia, 2020). $\mathrm{Al}$ respecto, en el modelo que se utiliza en este paper, se considera a Colombia en su conjunto, abstrayéndose de cuestiones regionales, lo que representa una interesante temática para futuras investigaciones.

\section{Modelo de CGE}

Con el fin de analizar diferentes escenarios asociados al shock migratorio, se utiliza un modelo de CGE estático real, que comparte características con el modelo estándar del IFPRI (Lofgren et al., 2002). En términos generales, se considera una economía pequeña y abierta; productores y consumidores maximizan beneficios y utilidad, respectivamente. A continuación, se describe brevemente el modelo, mientras la formulación matemática se explicita en el Apéndice B.

\section{V.1. Producción}

Cada sector productivo es representado por una actividad que maximiza beneficios, sujeto a la tecnología de producción que se presenta en la Figura 1. En primer lugar, se combina valor agregado y consumo intermedio en proporciones fijas. Se asume que la tecnología de producción de valor agregado es una función CES (Elasticidad de Sustitución Constante) anidada, mientras los insumos intermedios son utilizados en proporciones fijas. Se supone "capital-skill complementarity" (CSC; Griliches, 1969). La motivación de esto reside en cierta evidencia reciente. En particular, Parro (2013) utiliza un modelo de equilibrio general asumiendo CSC para estudiar el impacto de cambios en la tecnología y en los costos de comercio sobre la brecha salarial de calificación. El modelo le permite explicar una sustancial proporción del cambio observado en dicha brecha en una gran cantidad de economías. Entre los países en desarrollo, el modelo explica casi todo el incremento de la brecha en Argentina, más de la mitad en China, India y México, y la mitad en Chile y Colombia.

Entonces, en base a Krusell et al. (2000), se asume una tecnología de valor agregado con CSC. El primer nivel de dicha función considera dos compuestos de factores, que refieren a una

\footnotetext{
${ }^{5}$ Los migrantes se concentraron en dos focos económicos: Bogotá, la capital del país y la ciudad más grande en el departamento de Cundinamarca, y Medellín, la capital del departamento de Antioquia. Según Caruso et al. (2019), los inmigrantes venezolanos representan $0.31 \%$ de la población Cundinamarca y $0.59 \%$ de Antioquia.
} 
combinación de trabajadores no calificados y semi-calificados $(B D)$, por un lado, y de trabajadores calificados y capital $(H D)$, por otro. Luego, cada uno de estos agregados también es modelizado como una función CES. Formalmente, la cantidad producida de una actividad $a \epsilon A$ es una función de los factores de producción como sigue:

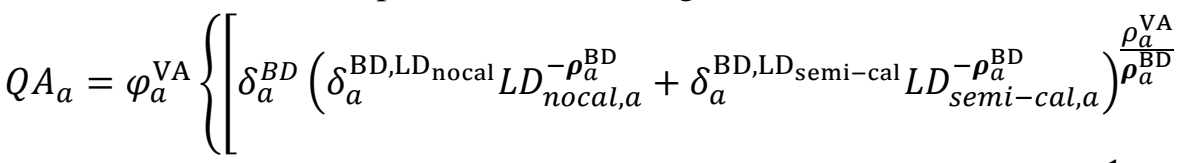

$$
\begin{aligned}
& \left.\left.+\delta_{a}^{H D}\left(\delta_{a}^{H D, K D} \overline{K D}_{a}^{-\rho_{a}^{\mathrm{HD}}}+\delta_{a}^{\mathrm{HD}, \mathrm{LD} \mathrm{cal}_{\mathrm{cal}}} L D_{c a l, a}^{-\boldsymbol{\rho}_{a}^{\mathrm{HD}}}\right)^{\frac{\rho_{a}^{\mathrm{VA}}}{\boldsymbol{\rho}_{a}^{\mathrm{HD}}}}\right]\right\}^{-\frac{1}{\rho_{a}^{\mathrm{VA}}}}
\end{aligned}
$$

donde $\varphi_{a}^{\mathrm{VA}}$ es un parámetro de eficiencia, $\delta_{a}^{j}$ es un parámetro de distribución; $\rho_{a}^{j}$ es un parámetro relacionado con la elasticidad de sustitución del agregado $j ; L D_{l, a}$ es el factor trabajo con nivel de calificación $l \epsilon=\{$ nocal, semi - cal, cal $\}$; y $\bar{K}_{a}$ es el factor capital sector-específico.

De este modo, se tienen tres elasticidades de sustitución: i) entre los agregados $B D_{a}$ y $H D_{a}$ $\sigma_{a}^{\mathrm{VA}}=\left(1+\rho_{a}^{\mathrm{VA}}\right)^{-1}$; ii) entre trabajadores no calificados y semi-calificados, $\sigma_{a}^{\mathrm{BD}}=(1+$ $\left.\rho_{a}^{\mathrm{BD}}\right)^{-1}$; y iii) entre trabajadores calificados y capital, $\sigma_{a}^{\mathrm{HD}}=\left(1+\rho_{a}^{\mathrm{HD}}\right)^{-1}$. Notar que esta modelización otorga una gran flexibilidad en la determinación de los grados de sustitución factorial ${ }^{6}$. Al respecto, en este trabajo se supone que $\sigma_{a}^{\mathrm{BD}}<\sigma_{a}^{\mathrm{VA}}$ y $\sigma_{a}^{\mathrm{HD}}<\sigma_{a}^{\mathrm{VA}}$, es decir, que es mayor la sustituibilidad entre los agregados de calificados-capital y semi-calificados-no calificados, que la sustituibilidad entre, por un lado, el capital y los trabajadores calificados, y entre los trabajadores semi-calificados y los no calificados, por otro.

\footnotetext{
${ }^{6}$ Sin embargo, se impone la restricción de que la elasticidad de sustitución entre calificados y no calificados es igual que aquella entre capital y no calificados y, análogamente, que la elasticidad de sustitución entre calificados y semicalificados es igual que aquella entre capital y semi-calificados. Esto es una simplificación para poder representar el hecho de que, consistentemente con la evidencia empírica, la elasticidad de sustitución entre el trabajo calificado y el trabajo no calificado (semi-calificado) es mayor que aquella entre trabajo calificado y el capital (ver Krussel et al. (2000)).
} 


\section{Figura 1. Tecnología de la Producción}

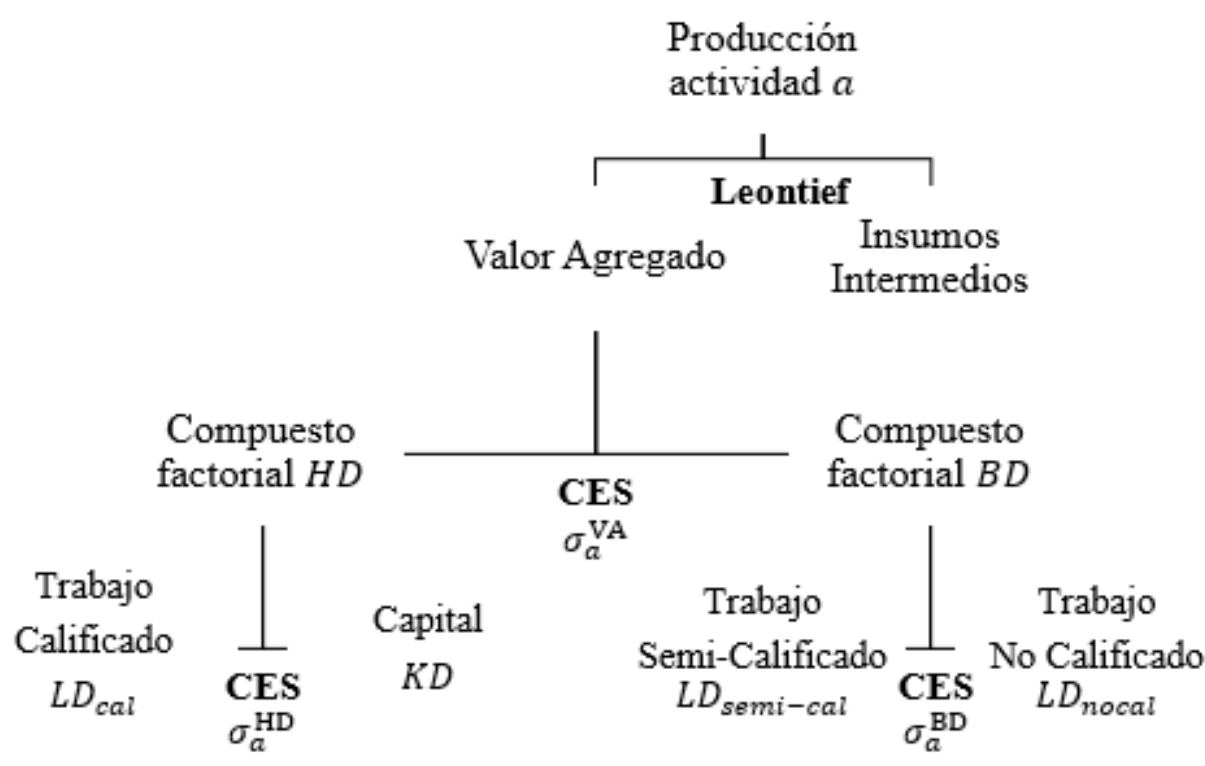

Fuente: Elaboración Propia.

\section{IV.2. Mercado de factores}

Se asume que el capital está en pleno empleo y es sector-específico, mientras que la oferta exógena de trabajo es desagregada en tres categorías en función de su nivel de calificación: no calificados, semi-calificados, y calificados. Se supone que cada tipo de trabajo es perfectamente móvil entre sectores, de modo que el salario varía entre categorías de calificación, pero no entre sectores dentro de una misma categoría. Adicionalmente, se introducen rigideces mediante de curvas de salario, las cuales permiten dar cuenta de la relación empírica negativa entre el nivel de salarios y la tasa de desempleo (Blanchflower y Oswald, 1994) ${ }^{7}$. Luego, el equilibrio en el mercado de trabajo se determina por la intersección de la demanda laboral y dicha curva de salarios.

\section{IV.3. Instituciones}

Se modela un único hogar representativo que recibe ingresos de los factores productivos que posee y transferencias del gobierno y del resto del mundo. Estos ingresos son destinados a pagar impuestos directos, a ahorrar, a realizar transferencias a otras instituciones, y al consumo de bienes. La demanda de consumo privado se deriva de la maximización de una función de utilidad de tipo Cobb-Douglas. El gobierno recauda a través de impuestos a los hogares, a la actividad, a

\footnotetext{
${ }^{7}$ Esta relación es compatible con diversas explicaciones teóricas, como la existencia de salarios de eficiencia (Shapiro y Stiglitz, 1984) o sindicatos con poder de negociación (Blanchflower et al., 1996), que pueden racionalizar desempleo de equilibrio.
} 
las ventas, y al comercio exterior, y recibe transferencias del resto del mundo. Luego, utiliza estos ingresos para comprar bienes para su consumo, realizar transferencias a los hogares y ahorrar.

\section{IV.4. Comercio Internacional}

Como ya se ha mencionado, se modela una economía pequeña, de modo que los precios internacionales están dados. Como es usual en la literatura, siguiendo a Armington (1969), se asume sustitución imperfecta entre bienes que difieren según su origen, de modo que la demanda de importaciones surge de una función CES que combina bienes domésticos e importados. Mientras tanto, la oferta de exportaciones se modela simétricamente a partir de una función CET (Elasticidad de Transformación Constante), la cual refleja el hecho de que los productores deciden destinar su producción al mercado doméstico o exportarla en función de los precios relativos.

\section{IV.5. Reglas de Cierre}

Finalmente, el modelo requiere la especificación de las reglas de cierre para tres balances macroeconómicos: el gobierno, el ahorro y la inversión y la balanza de pagos. Al respecto, en todas las simulaciones se asume que: i) el presupuesto del gobierno se equilibra mediante cambios en el ahorro público real; ii) la inversión se determina endógenamente según el nivel de ahorro; y iii) el ahorro del resto del mundo es exógeno (medido en moneda del resto del mundo), de modo que el tipo de cambio real varía endógenamente para igualar entradas y salidas de divisas. El numerario del modelo es el índice de precios al consumidor.

\section{Calibración}

Para la calibración del modelo se utiliza la SAM de Colombia en el año 2016 (Cicowiez, 2019), que incluye 10 sectores, 10 productos, factor capital, factor trabajo, 1 hogar representativo y otras cuentas (gobierno, ahorro e inversión, y el resto del mundo). Mediante el uso de la GEIH (DANE), el factor trabajo es desagregado en tres categorías, de acuerdo a su nivel de calificación.

\section{V.1. Descripción del año base}

A continuación, se describen aspectos de la economía colombiana que son claves para el análisis de nuestras simulaciones. Una descripción más extensiva es dejada en el Apéndice D, con el fin de facilitar la exposición. La estructura sectorial ${ }^{8}$ se muestra en la Tabla 1 incluyendo: participaciones en el valor agregado, en la producción, en la masa salarial, en las exportaciones

\footnotetext{
${ }^{8}$ El agrupamiento de los sectores es como sigue: agro=\{Agricultura, Ganadería, Caza y Silvicultura; Pesca $\}$; $\min =\{$ Explotación de Minas y Canteras $\} ;$ food $=\{$ Industria Alimenticia $\} ;$ refpet $=\{$ Refinación de Petróleo $\}$; $m a q=\{$ Fabricación de Maquinaria $\} ;$ othmnfc $=\{$ Otras Manufacturas $\} ;$ othind $=\{$ Electricidad, Gas y Agua; Construcción $\} ;$ trdtrns $=\{$ Comercio; Transporte, Almacenamiento y Comunicaciones $\} ; a d m p u b=\{$ Administración Pública $\}$; othsvc $=\{$ Hoteles y Restaurants; Intermediación Financiera y Seguros; Educación; Salud; Servicios Personales; Servicio Doméstico\}.
} 
y en las importaciones, así como la separación de la oferta doméstica entre exportaciones y ventas domésticas, y de la demanda doméstica entre importaciones y producción doméstica. Por ejemplo, el sector minero representa el $32.84 \%$ del total exportado (64.36\% de su producción). Sin embargo, en términos de valor agregado, dicho sector solo es una décima parte (4.40\%) de lo que representa el sector de otros servicios (44.95\%), que es el principal creador de valor agregado. Asimismo, se destaca la importancia del sector de otros servicios en la masa salarial (45.03\%). Mientras tanto, los sectores de maquinaria y otras manufacturas tienen las mayores participaciones en el total de importaciones, aunque solo el primero tiene una alta participación en su consumo (72.22\%).

Por otro lado, en la Tabla 2 se reporta la estructura de la demanda sectorial, la cual está dada, principalmente, por el consumo intermedio (41.87\%) y el consumo privado (33.04\%). Entre aquellos sectores cuya producción se destina en mayor medida al consumo intermedio se destacan la refinación de petróleo (71.79\%), el transporte (54.38\%), el agro (53.56 \%), y otras manufacturas $(52.32 \%)$. El sector minero es aquel con la mayor demanda sesgada hacia el mercado externo, ya que las exportaciones representan un 60.94\% de sus ventas, seguido de lejos por refinación de petróleo $(13.11 \%)$ y otras manufacturas $(12.60 \%)$. Por otro lado, otras industrias y maquinaria destinan una alta proporción de sus ventas a la inversión (61.17 y 45.21\%, respectivamente).

Tabla 1. Estructura sectorial (\%). Año base

\begin{tabular}{lccccccc}
\hline & VAshr & PRDshr & EMPshr & EXPshr & $\begin{array}{c}\text { EXP- } \\
\text { OUTshr }\end{array}$ & IMPshr & $\begin{array}{c}\text { IMP- } \\
\text { DEMshr }\end{array}$ \\
\hline Agro & 6.84 & 5.33 & 7.96 & 6.23 & 9.63 & 3.79 & 8.83 \\
Minería & 4.40 & 4.20 & 2.17 & 32.84 & 64.36 & 1.79 & 12.43 \\
Alimentos & 4.06 & 7.26 & 3.21 & 10.19 & 11.56 & 7.28 & 11.20 \\
Refinación de Petróleo & 1.05 & 2.98 & 0.41 & 6.70 & 18.55 & 6.76 & 22.20 \\
Maquinaria & 0.86 & 1.22 & 0.73 & 3.99 & 26.99 & 28.09 & 72.22 \\
Otras Manufacturas & 7.35 & 9.98 & 5.92 & 23.14 & 19.10 & 35.21 & 33.01 \\
Otras Industrias & 10.12 & 12.58 & 8.98 & 0.03 & 0.02 & 0.06 & 0.05 \\
Comercio y Transporte & 14.13 & 13.20 & 14.91 & 6.12 & 3.82 & 3.65 & 3.32 \\
Adm. Pública & 6.24 & 5.41 & 10.68 & 0.00 & 0.00 & 0.00 & 0.00 \\
Otros Servicios & 44.95 & 37.85 & 45.03 & 10.76 & 2.34 & 13.37 & 3.97 \\
\hline \multicolumn{1}{c}{ Total } & 100 & 100 & 100 & 100 & 8.24 & 100 & 11.34 \\
\hline
\end{tabular}

Fuente: Elaboración propia en base a la SAM 2016 (Cicowiez, 2019).

Notas: VAshr = participación sector en total valor agregado; PRDshr $=$ participación sector en total valor bruto producción; EMPshr = participación sector en total de masa salarial; EXPshr = participación sector en total exportaciones; EXP-OUTshr = participación exportaciones en producción; IMPshr = participación sector en total importaciones; IMP-DEPshr = participación importaciones en consumo. 
Tabla 2. Estructura de la Demanda (\%). Año base

\begin{tabular}{lcccccc}
\hline \multicolumn{1}{c}{ Bien } & $\begin{array}{c}\text { Consumo } \\
\text { Intermedio }\end{array}$ & $\begin{array}{c}\text { Consumo } \\
\text { Privado }\end{array}$ & $\begin{array}{c}\text { Consumo } \\
\text { Público }\end{array}$ & $\begin{array}{c}\text { Inversión } \\
\text { en Capital } \\
\text { Fijo }\end{array}$ & $\begin{array}{c}\text { Cambio en } \\
\text { Inventarios }\end{array}$ & $\begin{array}{c}\text { Exportaciones } \\
\text { Total }\end{array}$ \\
\hline Agro & 53.56 & 32.75 & 0.00 & 4.17 & 0.69 & 8.82 \\
Minería & 38.52 & 0.11 & 0.01 & 0.00 & 0.42 & 60.94 \\
Alimentos & 28.98 & 60.49 & 0.37 & 0.00 & 0.77 & 100 \\
Refinación de Petróleo & 71.79 & 15.14 & 0.00 & 0.00 & -0.03 & 13.11 \\
Maquinaria & 28.47 & 18.85 & 0.00 & 45.21 & 1.13 & 100 \\
Otras Manufacturas & 52.32 & 31.79 & 1.14 & 2.09 & 0.06 & 10.34 \\
Otras Industrias & 32.04 & 3.72 & 0.36 & 61.17 & 2.69 & 100 \\
Comercio y Transporte & 54.38 & 36.01 & 0.47 & 5.14 & 0.33 & 0.02 \\
Adm. Pública & 0.00 & 1.46 & 98.54 & 0.00 & 0.00 & 3.67 \\
Otros Servicios & 42.53 & 46.89 & 6.01 & 2.43 & 0.00 & 0.00 \\
\hline Total & 41.87 & 33.04 & 6.96 & 10.59 & 0.50 & 100 \\
\hline
\end{tabular}

Fuente: Elaboración propia en base a la SAM 2016 (Cicowiez, 2019).

Como ya fue mencionado, el factor trabajo es desagregado en función de su nivel de calificación, mediante el uso de la GEIH (DANE). Al respecto, en la Tabla 3 se muestra la participación de cada nivel de calificación en el total de empleados, por sector de actividad. El sector más empleo-intensivo ${ }^{9}$ en trabajo calificado es la administración pública. Una amplia mayoría de sectores son empleo-intensivos en trabajo semi-calificados: industria alimenticia, refinación de petróleo, maquinaria, transporte, otras manufacturas y servicios. Mientras tanto, los sectores agro, minería y otras industrias son intensivos en trabajo no calificado.

Complementariamente, en la Tabla 4 se reporta el salario horario promedio de cada categoría de trabajo, por sector. En promedio, la administración pública paga los salarios más altos para los trabajadores no calificados, mientras que queda en segundo lugar respecto a los semicalificados y los calificados, ya que, el salario más alto se encuentra en el sector minero para ambos niveles de calificación. Mientras tanto, el agro tiene los salarios horarios más bajos para los no calificados y los semi-calificados, mientras que, para los calificados, el salario promedio más bajo se encuentra en el sector de comercio y transporte.

\footnotetext{
${ }^{9}$ Aquí se denomina empleo-intensidad para diferenciarla de la intensidad relativa respecto a la masa salarial, como se emplea a continuación en la Tabla 5.
} 
Tabla 3. Participación de cada nivel de calificación en el total sectorial de empleados

\begin{tabular}{lcccc}
\hline & $\begin{array}{c}\text { No } \\
\text { calificados }\end{array}$ & Semi-Calificados & Calificados & Total \\
\hline Agro & 83.75 & 14.84 & 1.42 & 100 \\
Minería & 58.15 & 29.99 & 11.86 & 100 \\
Alimentos & 38.33 & 52.19 & 9.48 & 100 \\
Ref. Petróleo & 25.31 & 59.51 & 15.19 & 100 \\
Maquinaria & 19.45 & 60.55 & 20.00 & 100 \\
Otras Manufacturas & 41.70 & 48.96 & 9.34 & 100 \\
Otras Industrias & 56.64 & 35.77 & 7.59 & 100 \\
Comercio y Transporte & 43.88 & 48.09 & 8.03 & 100 \\
Adm. Pública & 5.78 & 48.09 & 46.13 & 100 \\
Otros Servicios & 33.82 & 41.93 & 24.25 & 100 \\
\hline
\end{tabular}

Fuente: Elaboración propia en base a GEIH 2016.

Tabla 4. Salario Horario Promedio de cada nivel de calificación, por sector

\begin{tabular}{lccc}
\hline & No calificados & Semicalificados & Calificados \\
\hline Agro & $2,282.71$ & $2,897.77$ & $10,212.70$ \\
Minería & $3,319.18$ & $8,013.31$ & $27,934.09$ \\
Alimentos & $3,178.97$ & $4,692.64$ & $13,671.67$ \\
Refinación de Petróleo & $5,114.95$ & $5,715.72$ & $15,555.28$ \\
Maquinaria & $4,425.78$ & $5,805.51$ & $12,952.72$ \\
Otras Manufacturas & $2,947.94$ & $4,362.73$ & $12,531.95$ \\
Otras Industrias & $3,606.94$ & $4,470.55$ & $14,777.96$ \\
Comercio y Transporte & $2,726.43$ & $3,992.04$ & $9,579.46$ \\
Adm. Pública & $5,915.17$ & $7,248.58$ & $16,584.59$ \\
Otros Servicios & $3,028.22$ & $4,658.40$ & $13,460.26$ \\
\hline Todos los sectores & $2,792.41$ & $4,409.11$ & $13,173.39$ \\
\hline
\end{tabular}

Fuente: Elaboración propia en base a GEIH 2016 y FMI.

Notas: El salario horario está expresado en pesos colombianos constantes deflactados por IPC $(100=$ enero de 2016).

Finalmente, se calculan las participaciones de cada categoría de trabajo en la masa salarial que, de acuerdo a la GEIH, genera cada sector productivo. Estas participaciones son aplicadas a las filas y columnas de la SAM que corresponden al factor trabajo para desagregarlo. Luego, es posible obtener la composición factorial del valor agregado, que se presenta en la Tabla 5. En lo que resta del paper, las referencias a intensidad factorial se hacen con respecto a esta tabla. En términos de pagos a los factores, los sectores más intensivos en trabajo (columna 1) son la administración pública $(84.92 \%)$ y el agro $(57.74 \%)$; mientras que aquellos más intensivos en capital (columna 5) son la refinación de petróleo (80.73\%), minería (75.82 \%), alimentos $(62.54 \%)$ y otras manufacturas $(60.74 \%)$. El resto de los sectores utiliza proporciones similares de ambos factores. En las columnas 2-4 se desagregan los pagos al trabajo, por nivel de calificación. Entre paréntesis se reportan las participaciones de cada categoría en la masa salarial sectorial. De aquí se destacan diversas observaciones. Los sectores de administración pública, otros servicios, y minería destinan una alta proporción de los pagos al factor trabajo al empleo 
calificado $(63.0 \%, 51.7 \%$, y $42.2 \%$, respectivamente). A pesar de que el sector minero emplea intensivamente trabajo no calificado (Tabla 3 ), dicha categoría es la menor en porcentaje de pagos al trabajo de dicho sector (24.2\%). El resto de los sectores, en general, destinan una mayor proporción de los pagos al trabajo a semi-calificados.

Tabla 5. Composición Factorial del Valor Agregado (\%). Año base

\begin{tabular}{lcccccc} 
& $\begin{array}{c}\text { Trabajo } \\
(1)\end{array}$ & $\begin{array}{c}\text { No calificado } \\
(2)\end{array}$ & $\begin{array}{c}\text { Semi-calificado } \\
(3)\end{array}$ & $\begin{array}{c}\text { Calificado } \\
(4)\end{array}$ & $\begin{array}{c}\text { Capital } \\
(5)\end{array}$ & $\begin{array}{c}\text { Total } \\
(6)\end{array}$ \\
\hline Agro & 57.74 & $44.29(76.7 \%)$ & $10.21(17.7 \%)$ & $3.24(5.6 \%)$ & 42.26 & 100 \\
Minería & 24.18 & $5.86(24.2 \%)$ & $8.11(33.5 \%)$ & $10.21(42.2 \%)$ & 75.82 & 100 \\
Alimentos & 37.46 & $9.11(24.3 \%)$ & $19.08(50.9 \%)$ & $9.27(24.7 \%)$ & 62.54 & 100 \\
Refinación de Petróleo & 19.27 & $3.69(19.2 \%)$ & $8.96(46.5 \%)$ & $6.62(34.3 \%)$ & 80.73 & 100 \\
Maquinaria & 42.30 & $5.37(12.7 \%)$ & $21.48(50.8 \%)$ & $15.46(36.5 \%)$ & 57.70 & 100 \\
Otras Manufacturas & 39.26 & $10.39(26.5 \%)$ & $19.05(48.5 \%)$ & $9.82(25.0 \%)$ & 60.74 & 100 \\
Otras industrias & 43.80 & $19.05(43.5 \%)$ & $14.99(34.2 \%)$ & $9.77(22.3 \%)$ & 56.20 & 100 \\
Comercio y Transporte & 52.45 & $16.40(31.3 \%)$ & $26.33(50.2 \%)$ & $9.73(18.5 \%)$ & 47.55 & 100 \\
Adm. Pública & 84.92 & $2.48(2.9 \%)$ & $28.92(34.1 \%)$ & $53.51(63.0 \%)$ & 15.08 & 100 \\
Otros Servicios & 50.35 & $8.16(16.2 \%)$ & $16.17(32.1 \%)$ & $26.02(51.7 \%)$ & 49.65 & 100 \\
\hline Total & 49.58 & $13.01(27.0 \%)$ & $17.81(37.7 \%)$ & $18.76(35.4 \%)$ & 50.42 & 100 \\
\hline
\end{tabular}

Fuente: Elaboración propia en base a la SAM 2016 (Cicowiez, 2019).

\section{V.2. Elasticidades y análisis de sensibilidad}

La calibración, además, requiere otros datos complementarios, como diversas elasticidades, que son un determinante fundamental de los resultados. Nuestro modelo requiere valores para: i) elasticidad-desempleo del salario de cada categoría de trabajo; ii) elasticidades de la función de producción; iii) elasticidades de sustitución entre compras domésticas e importaciones (Armington); y iv) elasticidades de transformación entre ventas domésticas y exportaciones (CET). Estos parámetros pueden ser estimados o recopilados de la literatura. En este trabajo se opta por el segundo camino. La sensibilidad de los resultados es evaluada a través de diferentes supuestos en relación a la magnitud de elasticidades claves en nuestro análisis: la elasticidaddesempleo de los salarios, y las elasticidades de sustitución de la función de producción ${ }^{10}$. En la Tabla 6 se reportan las cuatro combinaciones de parámetros que se utilizarán.

\footnotetext{
${ }^{10}$ También se hicieron las simulaciones con otro set de elasticidades del comercio; los resultados no son diferentes de los presentados aquí y están disponibles en caso de ser necesario.
} 


\section{V.2.1. Elasticidad-desempleo del salario de cada categoría de trabajo}

Desde el trabajo de Blanchflower et al. (1994), la literatura suele encontrar que la elasticidad de la curva de salarios es de -0.1 para un amplio rango de países (Card, 1995; Blanchflower y Oswald, 1995). Para Colombia, Arango et al. (2010) encuentran valores entre -0,083 y -0,149, que son consistentes tanto con la evidencia internacional y nacional (Sánchez y Núñez, 1998). Sin embargo, no identifican heterogeneidades en base al nivel de calificación de los trabajadores. Al respecto, es lógico esperar que la rigidez del mercado laboral difiera entre niveles de calificación. En una economía como la colombiana, además, el nivel de calificación se correlaciona con la tasa de informalidad. Según la base de datos SEDLAC, en el año 2016, la tasa de informalidad de Colombia fue de $35.5 \%{ }^{11}$. Si se desagrega por nivel educativo, alcanzó el 59.5\% para los de baja educación, $25.6 \%$ para los de educación media, y $6.3 \%$ para los de alto nivel educativo.

Entonces, en este trabajo se asume que la elasticidad del salario respecto al nivel de desempleo es igual a -0.1 para las tres categorías de trabajo. Como ejercicio de sensibilidad, en otro grupo de simulaciones se hipotetiza que, cuanto mayor sea la calificación, menor (en valor absoluto) será la elasticidad de los salarios respecto al desempleo. En particular, en base al rango de elasticidades estimado por Arango et al. (2010), se asume que: $\eta_{\text {cal }}=-0.083, \eta_{\text {semi-cal }}=$ -0.1 y $\eta_{\text {nocal }}=-0.149$.

\section{V.2.2. Elasticidades de la función de producción}

Como se ha explicado en la sección 4, se asume que es mayor la sustituibilidad entre los agregados de calificados-capital y semi-calificados-no calificados, que aquella entre, por un lado, el capital y los trabajadores calificados, y entre los trabajadores semi-calificados y los no calificados, por otro. En su análisis para Estados Unidos, Krusell et al. (2000) encuentran una elasticidad de 1.67 entre el capital y el trabajo no calificado, y de 0.67 entre el capital y el trabajo calificado. En el trabajo ya mencionado, Parro (2013) adopta los valores de Krusell el al. (2000), y su modelo explica la mitad del incremento de la brecha de calificación en Colombia. Recientemente, Medina et al. (2018) encuentran una elasticidad entre trabajo calificado y no calificado de 1.47 para Colombia en el período 1984-2009. En el contexto del análisis de los retornos a la educación, Manacorda et al. (2010) encuentran valores de entre 3 para la elasticidad de sustitución entre el trabajo calificado y el no calificado en América Latina. Similarmente, Galiani et al. (2007) encuentran valores entre 2 y 4 . En definitiva, en este trabajo se adopta una aproximación conservadora estableciendo los valores de estas elasticidades en base a Krusell el al. (2000), de modo que: $\sigma_{a}^{\mathrm{VA}}=1.67$ y $\sigma_{a}^{\mathrm{HD}}=\sigma_{a}^{\mathrm{BD}}=0.67$. Sin embargo, como ejercicio de sensibilidad, en otro grupo de simulaciones se consideran elasticidades mayores siguiendo a Manacorda et al. (2010) y Galiani et al. (2017).

\footnotetext{
${ }^{11}$ Considerando la definición legal de informalidad, según la cual un trabajador es considerado informal si no tiene derecho a una jubilación al momento del retiro.
} 


\section{V.2.3. Elasticidades del comercio internacional}

Respecto a las elasticidades del comercio externo, Martín y Ramírez (2004) consideran un escenario de "elasticidades altas" en base a Light y Rutherford (2003), asumiendo que la elasticidad CET es igual 2, mientras que la elasticidad Armington asciende a 4. Sin embargo, también muestran resultados con "elasticidades medias" en base a Hernández, Prada y Ramírez (2001), pero duplican sus valores para tener en cuenta la posibilidad de que las elasticidades aumenten como resultado del tratado de libre comercio que están analizando. Light y Rutherford (2003), además, se refieren a un escenario de "elasticidades bajas" en el que ambas elasticidades son iguales 2. Los mismos valores son elegidos por Gracia y Zuleta (2005), quienes lo denominan "el escenario realista de elasticidades bajas". La misma estrategia es elegida por Vaughan Caro (2005). En este trabajo se toma un enfoque conservador respecto de los escenarios de "elasticidad altas" que suele considerar la literatura y se le asigna un valor de 2 tanto a las elasticidades CET como Armington ${ }^{12}$.

Tabla 6. Sensibilidad de los resultados: Sets de parámetros libres

\begin{tabular}{lcccc}
\hline & SIM 1 & SIM 2 & SIM 3 & SIM 4 \\
\cline { 2 - 4 } Tasa de desempleo & & & & \\
$\quad$ No calificados & 0.073 & 0.073 & 0.073 & 0.073 \\
$\quad$ Semi-calificados & 0.118 & 0.118 & 0.118 & 0.118 \\
$\quad$ Calificados & 0.095 & 0.095 & 0.095 & 0.095 \\
\hline Elasticidad curva de salarios & & & & -0.15 \\
$\quad$ No calificados & -0.10 & -0.15 & -0.10 & -0.10 \\
$\quad$ Semi-calificados & -0.10 & -0.10 & -0.10 & -0.08 \\
$\quad$ Calificados & -0.10 & -0.08 & -0.10 & 3.00 \\
\hline Elasticidad de sustitución entre & & & & 2.00 \\
$\quad$ Agregados BD y HD & 1.67 & 1.67 & 3.00 & 2.00 \\
$\quad$ Capital y trabajo calificado & 0.67 & 0.67 & 2.00 & 2.00 \\
$\quad$ Trabajo no calificado y semi-calificado & 0.67 & 0.67 & 2.00 & 2.00 \\
\hline Elasticidades del comercio internacional & 2.00 & 2.00 & & 2.00 \\
\hline
\end{tabular}

Fuente: Elaboración propia.

Notas: Las tasas de desempleo se fijan en los niveles de la Tabla A.6 (Fuente: GEIH [DANE]). Las elasticidades de la curva de salarios se establecen en base a Blanchflower y Oswald (1995) y Arango et al. (2010). Las elasticidades de sustitución se eligen siguiendo a Krusell et al. (2000), Manacorda et al. (2010) y Galiani et al. (2017). Las elasticidades del comercio internacional se establecen en base a Light y Rutherford (2003), Gracia y Zuleta (2005) y Vaughan Caro (2005).

\section{Simulaciones y resultados}

Se utiliza el modelo de CGE descripto en la sección 4 para evaluar el efecto aislado de un incremento de la fuerza laboral asociado a la inmigración venezolana que se incorpora a la PEA

12 Como ya fue mencionado, también se hicieron simulaciones con un set de elasticidades más bajas en base a Karl (2004) y Sánchez y Hernández (2004); los resultados no son diferentes de los presentados aquí y están disponibles en caso de ser necesario. 
de Colombia de 2016. En base a la información de la Tabla A.5, en el escenario 1 se simula el influjo acumulado de migrantes entre 2017 y 2019 (3.45\% de la PEA de 2016). Desagregándolo por nivel de calificación, este shock representa un aumento de $2.72 \%$ de no calificados, $4.34 \%$ de semi-calificados y $2.94 \%$ de calificados.

En el escenario 2, además del shock de oferta laboral, se considera un cambio en la cuenta de transferencia del resto del mundo a los hogares, asociado al envío de remesas de los migrantes. Según el Banco Mundial (2018), el envío promedio actual de remesas por venezolano es de USD 30 por mes, de modo que el envío anual de los 794,214 inmigrantes venezolanos sumaría USD 286 millones ( 0.87 billones de pesos, al tipo de cambio de $2016^{13}$ ).

Junto con los shocks anteriores, en el escenario 3 se simulan ciertas respuestas de política y ayuda internacional. Para ello, se consideran las estimaciones del costo fiscal del fenómeno migratorio en Colombia realizadas por el Banco Mundial (2018) en base a supuestos del DNP. Dichas estimaciones sugieren que se requerirá entre $0.26 \%$ y $0.41 \%$ del PIB para que la población migrante elegible tenga acceso a servicios públicos en un nivel similar al de la población local en el corto plazo. Según el PBI de 2016, esto representaría entre 2.33 y 3.54 billones de pesos. $\mathrm{Al}$ respecto, aquí se considera el límite inferior de este rango ( $0.26 \%$ del $\mathrm{PBI})$, que corresponde al costo de provisión de servicios parciales a la población migrante. Por otro lado, según el Banco Mundial (2018), a junio de 2018 se habían gestionado USD 84 millones de ayuda internacional para responder a la inmigración en Colombia. Sin embargo, solo se ejecutaron USD 4 millones debido a demoras en los desembolsos y problemas logísticos. Más aun, la mayoría de recursos se ejecutaron a través de ONG. Al respecto, en el escenario 3, además de los shocks de los escenarios 1 y 2 , y el shock de gasto público recién discutido, se considera que los USD 4 millones ( 0.012 billones de pesos) se transfieren al hogar del modelo. A modo de resumen, en la Tabla 7 se especifican los tres escenarios.

Tabla 7. Definición de escenarios

\begin{tabular}{llll}
\hline & \multicolumn{1}{c}{ Escenario 1 } & \multicolumn{1}{c}{ Escenario 2 } & \multicolumn{1}{c}{ Escenario 3 } \\
\hline $\begin{array}{l}\text { Oferta } \\
\text { Laboral }\end{array}$ & $\begin{array}{l}\text { No calificados: }+2.72 \% \\
\text { Semicalificados: }+4.34 \% \\
\text { Calificados: }+2.94 \%\end{array}$ & $\begin{array}{l}\text { No calificados: }+2.72 \% \\
\text { Semicalificados: }+4.34 \% \\
\text { Calificados: }+2.94 \%\end{array}$ & $\begin{array}{l}\text { No calificados: }+2.72 \% \\
\text { Semicalificados: }+4.34 \% \\
\text { Calificados: }+2.94 \%\end{array}$ \\
\hline $\begin{array}{l}\text { Remesas } \\
\text { pagadas }\end{array}$ & +0.87 billones & +0.87 billones \\
\hline & & c-food: +0.07 billones \\
casto público & & & $\begin{array}{l}\text { c-thind: }+0.16 \text { billones } \\
\text { c-admpub: }+0.02 \text { billones }\end{array}$ \\
& & & c-othsvc: +1.97 billones \\
\hline $\begin{array}{l}\text { Ayuda } \\
\text { internacional } \\
\text { a los hogares }\end{array}$ & & +0.012 billones \\
\hline
\end{tabular}

Fuente: Elaboración propia. Valores monetarios expresados en pesos colombianos. La desagregación del paquete fiscal se obtiene de Banco Mundial (2018, Página 121).

\footnotetext{
${ }^{13}$ Fuente: Fondo Monetario Internacional. Consultado el 15 de junio de 2020.
} 
Brevemente, una intuición de los efectos es como sigue. El shock de oferta tiene un impacto directo sobre el mercado laboral abaratando relativamente el factor trabajo, lo que induce un aumento de su demanda relativa (efecto sustitución). A su vez, el abaratamiento de costos induce un efecto escala de modo que la demanda de factores que son complementos brutos se incrementa, mientras que cae la de aquellos sustitutos brutos. Los impactos dependerán también de las rigideces en los mercados respectivos. Dado que los mercados laborales son modelados mediante curvas de salario, esto depende de la magnitud de la elasticidad-desempleo del salario real. Cuanto más pequeña (en valor absoluto) sea esta elasticidad, mayor será el peso del ajuste que recaiga sobre el nivel de empleo, mientras que los salarios reales reaccionarán poco.

En una economía abierta, el incremento de la abundancia relativa y el consecuente abaratamiento relativo de un factor, expanden la frontera de posibilidades de producción de forma sesgada hacia la producción de aquellos sectores que usan intensivamente dicho factor. Sin embargo, el ajuste de la estructura productiva está limitado por la presencia de rigideces, como la inmovilidad de factores productivos y una estructura productiva poco diversificada.

Los cambios en las remuneraciones reales de los factores productivos afectan los ingresos de los propietarios de dichos factores, su poder de compra y por ende el consumo, el ahorro, la inversión y otros componentes del PBI. A su vez, estos cambios en el nivel general de ingresos y de actividad económica afectan la recaudación impositiva, mientras que el impacto en el gasto público depende en gran medida de las respuestas de política. El efecto esperado sobre el nivel de precios es ambiguo y depende, en gran medida, de cómo se vean afectadas la oferta y la demanda agregada.

Los impactos sobre la balanza comercial determinan la variación del tipo de cambio requerida para ajustar las cuentas externas. En el caso en el que, además, se considere un shock de remesas hacia el exterior, una mayor suba del tipo de cambio real será necesaria para su corrección. Finalmente, la ayuda internacional transferida al hogar del modelo, relaja su restricción presupuestaria, expandiendo su capacidad de ahorro y de gasto.

Es necesario tener en cuenta que el modelo utilizado es incapaz de analizar todos los mecanismos a través de los cuales la migración potencialmente puede afectar a la economía del país receptor. Por ejemplo, el modelo no captura cambios en la tasa de participación de los nativos, o los efectos diferenciales sobre la productividad o sobre la recaudación fiscal como consecuencia de la incorporación de migrantes con diferentes niveles de calificación. Aun así, el modelo permite analizar impactos sectoriales y, a nivel agregado, efectos sobre los salarios, el desempleo, la brecha salarial de calificación, el PBI, y el bienestar, entre otros.

\section{VI.1. Resultados}

En esta sección se resumen los resultados de las simulaciones de los tres escenarios. Para facilitar la exposición, aquí se reportan los resultados de la SIM 1 (ver Tabla 6) para los tres escenarios descriptos en la Tabla 7, mientras se deja en el Apéndice D los resultados del resto de las simulaciones. En la Tabla 8 se muestran los impactos en el mercado laboral, el PBI y sus componentes, el presupuesto del gobierno y el bienestar. Los resultados no difieren entre escenarios, de modo que se describen en términos generales, excepto que haya un cambio diferencial. Probablemente, esto ocurre porque algunos de los shocks de los escenarios 2 y 3 no representan cambios significativos en magnitud. Por ejemplo, el shock de remesas representa solo el $0.09 \%$ del ingreso total del hogar en el año base, mientras que la ayuda internacional el 
$0.001 \%$. Por el contrario, el shock de gasto público es un incremento de aproximadamente $2 \%$ en el gasto de consumo del gobierno. De todos modos, todos estos shocks son importantes en sí mismos y tienen relevancia de política.

Respecto al mercado laboral, la tasa de desempleo aumenta en los tres escenarios, aunque los cambios son modestos, mientras que se evidencian caídas importantes en los salarios reales. Los impactos en el segmento de no calificados son relativamente menores, probablemente debido a que este grupo experimentó el menor shock de oferta, pero también por su alta participación en el valor agregado de sectores que se expanden fuertemente como el agro y otras industrias (ver Tabla 9). Además, dado que la caída en los salarios reales es mayor para calificados y semicalificados, las brechas de calificación caen.

En conjunto, el aumento en el desempleo y la caída en los salarios reales afectan negativamente el ingreso de los hogares. Sin embargo, estos cambios se evidencian en un marco de expansión de la PEA y del empleo, lo cual opera en el sentido opuesto. Además, la remuneración al capital crece en términos reales en todos los sectores a excepción de la administración pública, que es altamente intensiva en trabajo (ver Tabla D.2 del Apéndice D). En definitiva, el ingreso disponible de los hogares se incrementa, lo que se evidencia, por ejemplo, en el mayor consumo privado y la mayor recaudación del impuesto directo.

La intervención del gobierno mediante el shock de gasto público pareciera favorecer al segmento de trabajadores calificados, cuyo salario real cae menos y su empleo crece más en el escenario 3. Mientras tanto, la caída del salario real de no calificados es mayor, y el aumento del empleo es menor. Esto es esperable ya que el gasto público aumenta en mayor medida en el sector de otros servicios, que es intensivo en trabajo calificado.

Dado que el modelo es estático, es posible medir el cambio en el bienestar mediante las variaciones en los precios y el ingreso en base a la definición de la variación equivalente $(\mathrm{EV})^{14}$. La EV refiere al ingreso monetario adicional necesario para que el hogar goce del mismo bienestar en la situación post shock, a los precios iniciales. Se encuentra que el bienestar aumenta en todos los escenarios simulados.

Respecto a los agregados macro, la absorción crece en todos los escenarios de la mano del consumo privado y la inversión, esta última como resultado de un mayor ahorro agregado. En el escenario 3, el aumento exógeno del gasto público desplaza el gasto en inversión, mientras la ayuda internacional impulsa el consumo privado. Las exportaciones crecen más que las importaciones, de modo que el saldo comercial mejora, pero sigue siendo negativo. Esto está asociado con una depreciación real en todos los escenarios, que implica un aumento tanto de los precios de exportación, desincentivando las ventas domésticas, como del costo de las importaciones. Dicha depreciación es mayor en el escenario 2, que considera un aumento de las remesas hacia el resto del mundo. En el escenario 3, la mejora en el saldo comercial es menor, ya que las exportaciones se expanden menos y las importaciones crecen más. El crecimiento del PBI es prácticamente igual en los tres escenarios.

En relación a las cuentas públicas, el aumento del nivel de actividad, del ingreso de los hogares, y de la demanda de importaciones se traduce en un incremento de la recaudación. Como consecuencia de la especificación del modelo, los gastos del gobierno no varían en términos reales en los escenarios 1 y 2 , de modo que la suba de la recaudación se refleja en un aumento

${ }^{14}$ En un modelo dinámico, el supuesto de inversión endógena hace que la variación equivalente no sea un buen indicador de cambios en el bienestar, ya que variaciones en la inversión se traducen en cambios en el stock de capital del período siguiente. 
del ahorro público (disminución de la deuda pública). En el escenario 3, donde hay una suba exógena del gasto público, la deuda pública crece.

Tabla 8. Efectos sobre el Mercado Laboral y Agregados Macro. SIM 1

\begin{tabular}{|c|c|c|c|c|}
\hline & Base & Escenario 1 & Escenario 2 & Escenario 3 \\
\hline \multicolumn{5}{|l|}{ Mercado de trabajo } \\
\hline Empleo (cambio \% respecto a base) & 379.29 & $2.03 \%$ & $2.01 \%$ & $1.99 \%$ \\
\hline No calificados & 99.52 & $2.34 \%$ & $2.32 \%$ & $2.18 \%$ \\
\hline Semi-calificados & 136.25 & $2.55 \%$ & $2.52 \%$ & $2.51 \%$ \\
\hline Calificados & 143.52 & $1.33 \%$ & $1.31 \%$ & $1.37 \%$ \\
\hline Tasa de Desempleo (cambio en p.p.) & 0.10 & 0.01 & 0.01 & 0.01 \\
\hline No calificados & 0.07 & 0.00 & 0.00 & 0.00 \\
\hline Semi-calificados & 0.12 & 0.02 & 0.02 & 0.02 \\
\hline Calificados & 0.10 & 0.01 & 0.01 & 0.01 \\
\hline \multicolumn{5}{|l|}{ Salarios (cambio \% respecto a base) } \\
\hline No calificados & 0.95 & $-0.46 \%$ & $-0.49 \%$ & $-0.64 \%$ \\
\hline Semi-calificados & 0.95 & $-1.20 \%$ & $-1.22 \%$ & $-1.23 \%$ \\
\hline Calificados & 0.95 & $-1.38 \%$ & $-1.40 \%$ & $-1.34 \%$ \\
\hline \multicolumn{5}{|c|}{ Brecha de calificación (cambio \% respecto a base) } \\
\hline Calificados/Semicalificados & 1.00 & $-0.18 \%$ & $0.18 \%$ & $-0.12 \%$ \\
\hline Calificados/No Calificados & 1.00 & $-0.93 \%$ & $-0.91 \%$ & $-0.70 \%$ \\
\hline Semi-calificados/No Calificados & 1.00 & $-0.75 \%$ & $-0.74 \%$ & $-0.59 \%$ \\
\hline \multicolumn{5}{|c|}{ Resultados Macro (Cantidades reales) (cambio \% respecto a base). } \\
\hline Absorción & 922.25 & $0.93 \%$ & $0.82 \%$ & $0.92 \%$ \\
\hline Consumo Privado & 596.53 & $0.91 \%$ & $0.78 \%$ & $0.82 \%$ \\
\hline Consumo Público & 125.61 & - & - & $1.94 \%$ \\
\hline Formación de Capital Fijo & 191.15 & $1.66 \%$ & $1.54 \%$ & $0.62 \%$ \\
\hline Cambio en Inventarios & 8.96 & - & - & - \\
\hline Exportaciones & 127.12 & $1.15 \%$ & $1.43 \%$ & $1.01 \%$ \\
\hline Importaciones & 185.59 & $0.79 \%$ & $0.51 \%$ & $0.70 \%$ \\
\hline PBI a precios de mercado & 863.78 & $1.00 \%$ & $0.98 \%$ & $0.98 \%$ \\
\hline Impuestos Indirectos Netos & 98.77 & $0.97 \%$ & $0.91 \%$ & $0.96 \%$ \\
\hline PBI a costo de factores & 765.01 & $1.00 \%$ & $0.99 \%$ & $0.98 \%$ \\
\hline Tipo de Cambio Real & 1.00 & $0.35 \%$ & $0.55 \%$ & $0.23 \%$ \\
\hline \multicolumn{5}{|c|}{ Presupuesto del Gobierno (cambio \% respecto a base). } \\
\hline Impuestos Directos & 57.86 & $0.91 \%$ & $0.78 \%$ & $0.81 \%$ \\
\hline Impuestos Actividades & 22.71 & $0.96 \%$ & $0.93 \%$ & $0.97 \%$ \\
\hline Impuestos Ventas Domésticas & 71.37 & $1.08 \%$ & $1.03 \%$ & $1.02 \%$ \\
\hline Aranceles & 4.70 & $1.29 \%$ & $1.22 \%$ & $0.81 \%$ \\
\hline Impuestos a las Exportaciones & 0.00 & - & - & - \\
\hline Transferencias del RDM & -0.22 & $0.35 \%$ & $0.53 \%$ & $0.15 \%$ \\
\hline Total de Ingresos & 156.41 & $1.00 \%$ & $0.93 \%$ & $0.93 \%$ \\
\hline Gastos de Consumo & 125.61 & $-0.53 \%$ & $-0.55 \%$ & $1.46 \%$ \\
\hline Transferencias Domésticas & 43.37 & $0.00 \%$ & $0.00 \%$ & $0.00 \%$ \\
\hline Ahorro Público & -12.57 & $-17.78 \%$ & $-17.04 \%$ & $2.98 \%$ \\
\hline Total de Gastos & 156.41 & $1.00 \%$ & $0.93 \%$ & $0.93 \%$ \\
\hline \multicolumn{5}{|l|}{ Bienestar } \\
\hline Variación Equivalente & & 601.96 & 601.17 & 601.40 \\
\hline
\end{tabular}

Fuente: Elaboración propia.

Notas: El escenario 1 considera un aumento de la oferta laboral de: $2.72 \%$ para no calificados, $4.34 \%$ de semicalificados y de $2.94 \%$ para calificados. El escenario 2, además del shock del escenario 1, incluye un aumento de 0.87 billones de pesos de transferencias de los hogares al resto del mundo (remesas). El escenario 3, además de los shocks anteriores, considera un aumento de gasto público de 2.33 billones de pesos y un aumento de transferencias del resto del mundo a los hogares (ayuda internacional) por 0.012 billones de pesos. Todos los escenarios son simulados con el set de parámetros libres correspondientes a la simulación 1 (ver Tabla 6). La EV es expresada en billones de pesos. 
Avanzando con el análisis sectorial, en la Tabla 9 se reporta el cambio, en términos reales, en el producto, las exportaciones, las importaciones y las ventas domésticas. Todos los sectores expanden su producto, pero en mayor medida agro, alimentos, maquinaria, otras manufacturas, otras industrias, otros servicios y transporte. Además, del abaratamiento de costos, la producción se ve dinamizada por un mayor consumo tanto intermedio como privado, efecto que es particularmente mayor en agro, alimentos, refinación de petróleo, otras manufacturas, transporte y otros servicios. Además, la demanda de inversión impulsa el crecimiento de sectores como maquinaria y otras industrias. En línea con el crecimiento real de la producción, todos los sectores evidencian un incremento real de las exportaciones en los tres escenarios. Este aumento fue mayor en aquellos sectores relativamente intensivos en trabajo, como el agro, comercio y otros servicios. Análogamente, se expanden fuertemente las importaciones de minería, refinación de petróleo, maquinaria y otras industrias. En el escenario 2, la mayor depreciación cambiaria se asocia con la caída de las importaciones de algunos sectores. Las ventas domésticas de todos los sectores se incrementan en los tres escenarios.

Finalmente, la evaluación de la sensibilidad de los resultados se realiza a través de la inspección de las tablas presentadas en el Apéndice D. Respecto al mercado laboral (Tablas D.1 y D.2), las tasas de desempleo aumentan en todas las simulaciones, y en mayor medida en aquellas donde se consideran mayores elasticidades de sustitución entre factores productivos (SIM 3 y 4). Cuando se diferencian las elasticidades-desempleo del salario real entre categorías de trabajo, se tiene que el aumento en el desempleo es mayor (menor) para aquellos segmentos más rígidos (flexibles). Por ejemplo, en las SIM 2 y 4, donde se asume que la elasticidad desempleo del salario real de los trabajadores no calificados es mayor, el aumento en la tasa de desempleo es menor que en las SIM 1 y 3, respectivamente, ya que parte del impacto es absorbido por mayores caídas en los salarios. Lo contrario ocurre para los trabajadores calificados, cuyo segmento se asume que es más rígido en las SIM 2 y 4, de modo que un mayor peso del ajuste recae en los niveles de empleo, respecto a las SIM 1 y 3 , respectivamente.

Por otro lado, en las SIM 3 y 4, el aumento en la tasa de desempleo y la caída en los salarios reales de los trabajadores semi-calificados son significativamente menores que las de los otros segmentos. Esto sugiere que, cuando se consideran mayores elasticidades de sustitución factorial, el empleo semi-calificados tiende a crecer más (caer menos) antes aumentos (disminuciones) en el nivel de producción, que el resto de las categorías de trabajo, lo que podría obedecer a la alta participación en el valor agregado que representa en una amplia mayoría de sectores (Tabla 5).

El crecimiento del PBI y del bienestar es mayor en escenarios con mayores elasticidades de sustitución, no siendo tan diferentes entre casos con diferentes elasticidades salario-desempleo (Tablas D.3 y D.4). Esto sugiere que cuanto más flexible sea la economía asignando recursos en la producción, mayores ganancias (menores pérdidas) experimentará ante un shock positivo (negativo). Respecto a las cuentas públicas, cuanto mayores son las elasticidades de sustitución, mayores son las ganancias reales en términos de ingresos fiscales (Tabla D.5).

Respecto a los impactos sectoriales (Tablas D.6-D.9), nuevamente, las mayores diferencias se encuentran en las SIM 3 y 4, que consideran elasticidades de sustitución factorial más grandes. En esos casos, el ajuste de la estructura productiva hacia sectores que usan intensivamente trabajo es más pronunciado, de modo que se expanden fuertemente (tanto en términos de producto como de exportaciones netas) sectores como el agro y alimentos, mientras caen minería, refinación de petróleo, otras industrias y otros servicios. 
En resumen, el análisis de la sensibilidad de los resultados sugiere que los hallazgos principales son robustos, en particular, en relación a su interpretación cualitativa. La consideración de elasticidades de sustitución factorial mayores induce un aumento en valor absoluto de los cambios, pero las intuiciones básicas se mantienen. En este sentido, consideramos que es aconsejable ser prudente con la elección de dichas elasticidades, acorde con un proceso de ajuste de corto plazo, de modo que nuestros resultados preferidos son aquellos que corresponden al set de parámetros libres más conservadores. 
Tabla 9. Impactos Sectoriales. Simulación 1 (cambio \% respecto a base)

\begin{tabular}{|c|c|c|c|c|}
\hline & Base & Escenario 1 & Escenario 2 & Escenario 3 \\
\hline \multicolumn{5}{|l|}{ Producto Real } \\
\hline Agro & 82.24 & $1.19 \%$ & $1.22 \%$ & $1.16 \%$ \\
\hline Minería & 64.86 & $0.64 \%$ & $0.74 \%$ & $0.54 \%$ \\
\hline Alimentos & 112.05 & $1.04 \%$ & $1.05 \%$ & $1.07 \%$ \\
\hline Refinación de Petróleo & 45.94 & $0.59 \%$ & $0.65 \%$ & $0.55 \%$ \\
\hline Maquinaria & 18.78 & $1.22 \%$ & $1.28 \%$ & $1.04 \%$ \\
\hline Otras Manufacturas & 154.04 & $1.15 \%$ & $1.23 \%$ & $0.98 \%$ \\
\hline Otras Industrias & 194.19 & $1.44 \%$ & $1.34 \%$ & $0.74 \%$ \\
\hline Comercio y Transporte & 203.79 & $1.13 \%$ & $1.11 \%$ & $1.06 \%$ \\
\hline Adm. Pública & 83.57 & $0.02 \%$ & $0.02 \%$ & $0.04 \%$ \\
\hline Otros Servicios & 584.25 & $1.00 \%$ & $0.97 \%$ & $1.15 \%$ \\
\hline Total & 1543.70 & $1.02 \%$ & $1.01 \%$ & $0.96 \%$ \\
\hline \multicolumn{5}{|l|}{ Exportaciones Reales } \\
\hline Agro & 7.92 & $1.94 \%$ & $2.35 \%$ & $1.82 \%$ \\
\hline Minería & 41.74 & $0.46 \%$ & $0.60 \%$ & $0.45 \%$ \\
\hline Alimentos & 12.95 & $1.59 \%$ & $1.97 \%$ & $1.41 \%$ \\
\hline Refinación de Petróleo & 8.52 & $0.28 \%$ & $0.47 \%$ & $0.26 \%$ \\
\hline Maquinaria & 5.07 & $1.18 \%$ & $1.37 \%$ & $1.25 \%$ \\
\hline Otras Manufacturas & 29.42 & $1.38 \%$ & $1.71 \%$ & $1.20 \%$ \\
\hline Otras Industrias & 0.03 & $1.22 \%$ & $1.55 \%$ & $1.34 \%$ \\
\hline Comercio y Transporte & 7.78 & $2.02 \%$ & $2.39 \%$ & $1.76 \%$ \\
\hline Adm. Pública & 0.00 & $2.29 \%$ & $2.70 \%$ & $1.88 \%$ \\
\hline Otros Servicios & 13.68 & $1.93 \%$ & $2.35 \%$ & $1.38 \%$ \\
\hline Total & 127.12 & $1.15 \%$ & $1.43 \%$ & $1.01 \%$ \\
\hline \multicolumn{5}{|l|}{ Importaciones Reales } \\
\hline Agro & 7.04 & $0.27 \%$ & $-0.14 \%$ & $0.35 \%$ \\
\hline Minería & 3.33 & $1.49 \%$ & $1.40 \%$ & $0.96 \%$ \\
\hline Alimentos & 13.50 & $0.34 \%$ & $-0.11 \%$ & $0.64 \%$ \\
\hline Refinación de Petróleo & 12.54 & $1.06 \%$ & $0.91 \%$ & $0.98 \%$ \\
\hline Maquinaria & 52.14 & $1.29 \%$ & $1.13 \%$ & $0.68 \%$ \\
\hline Otras Manufacturas & 65.34 & $0.80 \%$ & $0.53 \%$ & $0.65 \%$ \\
\hline Otras Industrias & 0.11 & $1.67 \%$ & $1.13 \%$ & $0.15 \%$ \\
\hline Comercio y Transporte & 6.78 & $0.17 \%$ & $-0.26 \%$ & $0.30 \%$ \\
\hline Adm. Pública & 0.00 & $-2.19 \%$ & $-2.58 \%$ & $-1.76 \%$ \\
\hline Otros Servicios & 24.82 & $0.02 \%$ & $-0.46 \%$ & $0.91 \%$ \\
\hline Total & 185.59 & $0.79 \%$ & $0.51 \%$ & $0.70 \%$ \\
\hline \multicolumn{5}{|l|}{ Ventas Domésticas } \\
\hline Agro & 74.32 & $1.10 \%$ & $1.09 \%$ & $1.09 \%$ \\
\hline Minería & 23.12 & $0.98 \%$ & $1.00 \%$ & $0.70 \%$ \\
\hline Alimentos & 99.10 & $0.96 \%$ & $0.93 \%$ & $1.02 \%$ \\
\hline Refinación de Petróleo & 37.42 & $0.67 \%$ & $0.69 \%$ & $0.62 \%$ \\
\hline Maquinaria & 13.71 & $1.23 \%$ & $1.25 \%$ & $0.97 \%$ \\
\hline Otras Manufacturas & 124.62 & $1.09 \%$ & $1.11 \%$ & $0.93 \%$ \\
\hline Otras Industrias & 194.16 & $1.44 \%$ & $1.34 \%$ & $0.74 \%$ \\
\hline Comercio y Transporte & 196.01 & $1.09 \%$ & $1.06 \%$ & $1.03 \%$ \\
\hline Adm. Pública & 83.57 & $0.02 \%$ & $0.02 \%$ & $0.04 \%$ \\
\hline Otros Servicios & 570.57 & $0.97 \%$ & $0.94 \%$ & $1.14 \%$ \\
\hline Total & 1416.58 & $1.01 \%$ & $0.98 \%$ & $0.95 \%$ \\
\hline
\end{tabular}

Fuente: Elaboración propia.

Notas: El escenario 1 considera un aumento de la oferta laboral de: $2.72 \%$ para no calificados, $4.34 \%$ de semicalificados y de $2.94 \%$ para calificados. El escenario 2, además del shock del escenario 1, incluye un aumento de 0.87 billones de pesos de transferencias de los hogares al resto del mundo (remesas). El escenario 3, además de los shocks anteriores, considera un aumento de gasto público de 2.33 billones de pesos y un aumento de transferencias del resto del mundo a los hogares (ayuda internacional) por 0.012 billones de pesos. Todos los escenarios son simulados con el set de parámetros libres correspondientes a la simulación 1 (ver Tabla 6). 


\section{VI.2. Robustez respecto del shock de oferta}

Finalmente, como análisis de robustez adicional se considera el hecho de que los episodios de migración forzada suelen estar asociados a la imposibilidad de los migrantes de acreditar sus estudios en el país receptor. Si esto fuera así, aun teniendo un alto nivel de calificación, los trabajadores migrantes deberían optar por trabajos de baja calificación. En otras palabras, la distribución del shock de oferta laboral de los escenarios 1-3 podría estar sobreestimando los incrementos para calificados y semi-calificados, mientras que subestimaría el shock para los no calificados ${ }^{15}$. Al respecto, como ejercicio de robustez, se repiten los escenarios 1-3 pero considerando que los 794,214 migrantes venezolanos se adicionan a la oferta laboral de no calificados, lo que representa un aumento de $8.1 \%$ sobre la PEA de dicho segmento en el año $2016^{16}$. Los resultados se presentan en las Tablas 10 y 11.

Las principales diferencias con respecto a los resultados de los escenarios 1-3 se encuentran en el mercado laboral. Al respecto, el incremento del empleo de no calificados casi duplica al de los escenarios 1-3, mientras que lo contrario ocurre para semi-calificados y calificados. Asimismo, aunque los cambios siguen siendo modestos, también es algo mayor el incremento del desempleo de no calificados, pero el desempleo de los semi-calificados cae, lo cual está en parte relacionado con la complementariedad entre estas categorías de trabajo. Finalmente, los salarios de los no calificados sufren sustanciales caídas mientras que, a diferencia de los escenarios 1-3, el salario de calificados y semi-calificados sube. En consecuencia, las brechas de calificación se incrementan.

Los impactos sobre el resto de los indicadores son análogos a los de los escenarios 1-3, aunque algo menores en magnitud. Por ejemplo, el PBI crece 0.22 puntos porcentuales menos que en los escenarios en donde los trabajadores pueden acreditar sus estudios. El crecimiento del producto y las exportaciones netas de sectores altamente intensivos en trabajo no calificado es mayor (por ejemplo, agro, alimentos y otras industrias). Por el contrario, el modesto crecimiento en el producto de refinación de petróleo se asocia con una caída en sus exportaciones y un incremento de sus importaciones. Nuevamente, en el escenario 5, la mayor depreciación cambiaria induce en algunos sectores la caída de sus importaciones.

\footnotetext{
15 Sin embargo, como ya se ha mencionado, esto no pareciera ser una característica del fenómeno migratorio de venezolanos hacia Colombia. Según Banco Mundial (2018; pág. 22), el mayor impacto de la migración en el mercado laboral ha sido la pérdida de empleos formales debido a que la población migrante cuenta con un nivel mayor de educación y competencias en comparación con la población de áreas receptoras.

${ }^{16}$ Los resultados de los ejercicios de sensibilidad para los escenarios 4-6 no se reportan aquí por una cuestión de brevedad y están disponibles en caso de ser necesario.
} 
Tabla 10. Efectos sobre el Mercado Laboral y Agregados Macro. SIM 1

\begin{tabular}{|c|c|c|c|c|}
\hline & Base & Escenario 4 & Escenario 5 & Escenario 6 \\
\hline \multicolumn{5}{|l|}{ Mercado de trabajo } \\
\hline Empleo (cambio \% respecto a base) & 379.29 & $1.60 \%$ & $1.57 \%$ & $1.55 \%$ \\
\hline No calificados & 99.52 & $4.35 \%$ & $4.32 \%$ & $4.16 \%$ \\
\hline Semi-calificados & 136.25 & $1.04 \%$ & $1.01 \%$ & $1.00 \%$ \\
\hline Calificados & 143.52 & $0.22 \%$ & $0.20 \%$ & $0.26 \%$ \\
\hline Tasa de Desempleo (cambio en p.p.) & 0.10 & 0.00 & 0.00 & 0.00 \\
\hline No calificados & 0.07 & 0.03 & 0.03 & 0.03 \\
\hline Semi-calificados & 0.12 & -0.01 & -0.01 & -0.01 \\
\hline Calificados & 0.10 & 0.00 & 0.00 & 0.00 \\
\hline \multicolumn{5}{|l|}{ Salarios (cambio \%) } \\
\hline No calificados & 0.95 & $-3.58 \%$ & $-3.61 \%$ & $-3.74 \%$ \\
\hline Semi-calificados & 0.95 & $0.81 \%$ & $0.79 \%$ & $0.78 \%$ \\
\hline Calificados & 0.95 & $0.21 \%$ & $0.19 \%$ & $0.25 \%$ \\
\hline \multicolumn{5}{|c|}{ Brecha de calificación (cambio \% respecto a base) } \\
\hline Calificados/Semicalificados & 1.00 & $-0.60 \%$ & $-0.59 \%$ & $-0.52 \%$ \\
\hline Calificados/No Calificados & 1.00 & $3.93 \%$ & $3.94 \%$ & $4.14 \%$ \\
\hline Semi-calificados/No Calificados & 1.00 & $4.56 \%$ & $4.56 \%$ & $4.69 \%$ \\
\hline \multicolumn{5}{|c|}{ Resultados Macro (Cantidades reales) (cambio \% respecto a base). } \\
\hline Absorción & 922.25 & $0.73 \%$ & $0.62 \%$ & $0.71 \%$ \\
\hline Consumo Privado & 596.53 & $0.72 \%$ & $0.58 \%$ & $0.62 \%$ \\
\hline Consumo Público & 125.61 & - & - & $1.94 \%$ \\
\hline Formación de Capital Fijo & 191.15 & $1.27 \%$ & $1.14 \%$ & $0.20 \%$ \\
\hline Cambio en Inventarios & 8.96 & - & - & - \\
\hline Exportaciones & 127.12 & $0.98 \%$ & $1.25 \%$ & $0.83 \%$ \\
\hline Importaciones & 185.59 & $0.67 \%$ & $0.39 \%$ & $0.57 \%$ \\
\hline PBI a precios de mercado & 863.78 & $0.78 \%$ & $0.76 \%$ & $0.75 \%$ \\
\hline Impuestos Indirectos Netos & 98.77 & $0.72 \%$ & $0.65 \%$ & $0.70 \%$ \\
\hline PBI a costo de factores & 765.01 & $0.78 \%$ & $0.77 \%$ & $0.76 \%$ \\
\hline Tipo de Cambio Real & 1.00 & $0.22 \%$ & $0.42 \%$ & $0.10 \%$ \\
\hline \multicolumn{5}{|c|}{ Presupuesto del Gobierno (cambio \% respecto a base). } \\
\hline Impuestos Directos & 57.86 & $0.71 \%$ & $0.58 \%$ & $0.61 \%$ \\
\hline Impuestos Actividades & 22.71 & $0.75 \%$ & $0.72 \%$ & $0.76 \%$ \\
\hline Impuestos Ventas Domésticas & 71.37 & $0.84 \%$ & $0.80 \%$ & $0.78 \%$ \\
\hline Aranceles & 4.70 & $0.91 \%$ & $0.85 \%$ & $0.42 \%$ \\
\hline Retenciones & 0.00 & - & - & - \\
\hline Transferencias del RDM & -0.22 & $0.19 \%$ & $0.37 \%$ & $-0.01 \%$ \\
\hline Total de Ingresos & 156.41 & $0.78 \%$ & $0.71 \%$ & $0.71 \%$ \\
\hline Gastos de Consumo & 125.61 & $0.19 \%$ & $0.18 \%$ & $2.19 \%$ \\
\hline Transferencias Domésticas & 43.37 & $0.00 \%$ & $0.00 \%$ & $0.00 \%$ \\
\hline Ahorro Público & -12.57 & $-7.81 \%$ & $-7.08 \%$ & $13.06 \%$ \\
\hline Total de Gastos & 156.41 & $0.78 \%$ & $0.71 \%$ & $0.71 \%$ \\
\hline \multicolumn{5}{|l|}{ Bienestar } \\
\hline Variación Equivalente & & 600.80 & 600.01 & 600.20 \\
\hline
\end{tabular}

Fuente: Elaboración propia.

Notas: El escenario 4 considera un aumento de la oferta laboral de: $8.1 \%$ para no calificados. El escenario 5, además del shock del escenario 4, incluye un aumento de 0.87 billones de pesos de transferencias de los hogares al resto del mundo (remesas). El escenario 6, además de los shocks anteriores, considera un aumento de gasto público de 2.33 billones de pesos y un aumento de transferencias del resto del mundo a los hogares (ayuda internacional) por 0.012 billones de pesos. Todos los escenarios son simulados con el set de parámetros libres correspondientes a la simulación 1 (ver Tabla 6). La EV es expresada en billones de pesos. 
Tabla 11. Impactos Sectoriales. Simulación 1 (cambio \% respecto a base)

\begin{tabular}{|c|c|c|c|c|}
\hline & Base & Escenario 4 & Escenario 5 & Escenario 6 \\
\hline \multicolumn{5}{|l|}{ Producto Real } \\
\hline Agro & 82.24 & $2.11 \%$ & $2.14 \%$ & $2.07 \%$ \\
\hline Minería & 64.86 & $0.43 \%$ & $0.53 \%$ & $0.33 \%$ \\
\hline Alimentos & 112.05 & $1.17 \%$ & $1.18 \%$ & $1.20 \%$ \\
\hline Refinación de Petróleo & 45.94 & $0.35 \%$ & $0.40 \%$ & $0.31 \%$ \\
\hline Maquinaria & 18.78 & $0.47 \%$ & $0.54 \%$ & $0.30 \%$ \\
\hline Otras Manufacturas & 154.04 & $0.81 \%$ & $0.89 \%$ & $0.63 \%$ \\
\hline Otras Industrias & 194.19 & $1.12 \%$ & $1.02 \%$ & $0.41 \%$ \\
\hline Comercio y Transporte & 203.79 & $0.89 \%$ & $0.87 \%$ & $0.81 \%$ \\
\hline Adm. Pública & 83.57 & $0.01 \%$ & $0.01 \%$ & $0.02 \%$ \\
\hline Otros Servicios & 584.25 & $0.60 \%$ & $0.57 \%$ & $0.75 \%$ \\
\hline Total & 1543.70 & $0.80 \%$ & $0.79 \%$ & $0.73 \%$ \\
\hline \multicolumn{5}{|l|}{ Exportaciones Reales } \\
\hline Agro & 7.92 & $5.20 \%$ & $5.61 \%$ & $5.03 \%$ \\
\hline Minería & 41.74 & $0.29 \%$ & $0.43 \%$ & $0.27 \%$ \\
\hline Alimentos & 12.95 & $1.98 \%$ & $2.36 \%$ & $1.77 \%$ \\
\hline Refinación de Petróleo & 8.52 & $-0.07 \%$ & $0.13 \%$ & $-0.08 \%$ \\
\hline Maquinaria & 5.07 & $0.16 \%$ & $0.35 \%$ & $0.24 \%$ \\
\hline Otras Manufacturas & 29.42 & $0.84 \%$ & $1.17 \%$ & $0.65 \%$ \\
\hline Otras Industrias & 0.03 & $1.89 \%$ & $2.23 \%$ & $1.99 \%$ \\
\hline Comercio y Transporte & 7.78 & $1.42 \%$ & $1.79 \%$ & $1.15 \%$ \\
\hline Adm. Pública & 0.00 & $-0.08 \%$ & $0.32 \%$ & $-0.48 \%$ \\
\hline Otros Servicios & 13.68 & $0.72 \%$ & $1.14 \%$ & $0.17 \%$ \\
\hline Total & 127.12 & $0.98 \%$ & $1.25 \%$ & $0.83 \%$ \\
\hline \multicolumn{5}{|l|}{ Importaciones Reales } \\
\hline Agro & 7.04 & $-1.52 \%$ & $-1.93 \%$ & $-1.43 \%$ \\
\hline Minería & 3.33 & $1.12 \%$ & $1.02 \%$ & $0.57 \%$ \\
\hline Alimentos & 13.50 & $0.17 \%$ & $-0.28 \%$ & $0.47 \%$ \\
\hline Refinación de Petróleo & 12.54 & $0.96 \%$ & $0.81 \%$ & $0.87 \%$ \\
\hline Maquinaria & 52.14 & $1.02 \%$ & $0.87 \%$ & $0.40 \%$ \\
\hline Otras Manufacturas & 65.34 & $0.76 \%$ & $0.49 \%$ & $0.61 \%$ \\
\hline Otras Industrias & 0.11 & $0.36 \%$ & $-0.17 \%$ & $-1.16 \%$ \\
\hline Comercio y Transporte & 6.78 & $0.33 \%$ & $-0.11 \%$ & $0.45 \%$ \\
\hline Adm. Pública & 0.00 & $0.09 \%$ & $-0.31 \%$ & $0.54 \%$ \\
\hline Otros Servicios & 24.82 & $0.47 \%$ & $-0.01 \%$ & $1.36 \%$ \\
\hline Total & 185.59 & $0.67 \%$ & $0.39 \%$ & $0.57 \%$ \\
\hline \multicolumn{5}{|l|}{ Ventas Domésticas } \\
\hline Agro & 74.32 & $1.78 \%$ & $1.77 \%$ & $1.75 \%$ \\
\hline Minería & 23.12 & $0.70 \%$ & $0.72 \%$ & $0.42 \%$ \\
\hline Alimentos & 99.10 & $1.07 \%$ & $1.03 \%$ & $1.12 \%$ \\
\hline Refinación de Petróleo & 37.42 & $0.45 \%$ & $0.47 \%$ & $0.40 \%$ \\
\hline Maquinaria & 13.71 & $0.59 \%$ & $0.61 \%$ & $0.32 \%$ \\
\hline Otras Manufacturas & 124.62 & $0.80 \%$ & $0.83 \%$ & $0.63 \%$ \\
\hline Otras Industrias & 194.16 & $1.12 \%$ & $1.02 \%$ & $0.40 \%$ \\
\hline Comercio y Transporte & 196.01 & $0.87 \%$ & $0.84 \%$ & $0.80 \%$ \\
\hline Adm. Pública & 83.57 & $0.01 \%$ & $0.01 \%$ & $0.02 \%$ \\
\hline Otros Servicios & 570.57 & $0.60 \%$ & $0.56 \%$ & $0.76 \%$ \\
\hline Total & 1416.58 & $0.78 \%$ & $0.75 \%$ & $0.72 \%$ \\
\hline
\end{tabular}

Fuente: Elaboración propia.

Notas: El escenario 4 considera un aumento de la oferta laboral de: $8.1 \%$ para no calificados. El escenario 5, además del shock del escenario 4, incluye un aumento de 0.87 billones de pesos de transferencias de los hogares al resto del mundo (remesas). El escenario 6, además de los shocks anteriores, considera un aumento de gasto público de 2.33 billones de pesos y un aumento de transferencias del resto del mundo a los hogares (ayuda internacional) por 0.012 billones de pesos. Todos los escenarios son simulados con el set de parámetros libres correspondientes a la simulación 1 (ver Tabla 6). 


\section{Conclusiones}

Colombia es el mayor receptor de migrantes que abandonan Venezuela debido a la severa crisis que se agudizó en los últimos años. Este influjo masivo se aceleró fuertemente desde agosto de 2016, cuando se levantó el bloqueo de las fronteras luego de estar cerradas durante un año. Actualmente, se estima que cerca de 2 millones de venezolanos han ingresado a Colombia entre 2015 y 2019.

En consecuencia, han emergido serias preocupaciones acerca del impacto de tamaña migración sobre la economía colombiana. Al respecto, este paper sigue un enfoque diferente al de la extensa literatura que analiza los impactos de la inmigración en las economías receptoras a través de estimaciones de forma reducida de salarios y empleo. A pesar de que dichos trabajos proveen evidencia útil acerca de los efectos directos en el mercado laboral, no tienen en cuenta la multiplicidad de efectos de equilibrio general.

El presente trabajo contribuye al análisis de dichos efectos mediante simulaciones en un modelo de CGE, haciendo foco en la caracterización de los inmigrantes en función de su nivel de calificación. A diferencia de otros fenómenos migratorios masivos, este tiene la particularidad de que existe una relativa homogeneidad cultural entre las poblaciones de origen y de destino. Entonces, es razonable suponer sustitución perfecta entre estos grupos, mientras se divide a los trabajadores en categorías imperfectamente sustitutas, por su nivel de calificación.

Diferentes escenarios contrafácticos asociados al shock migratorio son considerados, evaluando impactos sectoriales y a nivel agregado. Además del shock de oferta laboral, se simulan cambios en la cuenta de remesas de la balanza de pagos, intervenciones de política y ayuda internacional. El modelo es calibrado mediante una SAM actualizada y encuestas de hogares.

Los principales resultados son los siguientes. A pesar de la caída en los salarios reales y el aumento del desempleo, la migración tiende a aumentar el nivel general de ingresos, la actividad económica, y la recaudación impositiva. Asimismo, el mayor nivel de ahorro agregado financia un incremento en la inversión. El bienestar, medido por la variación equivalente, aumenta. El aumento de gasto público simulado en respuesta al shock migratorio tiende a favorecer más al segmento de trabajadores calificados, ya que expande la demanda de sectores intensivos en dicho factor. Sin embargo, el modelo es incapaz de medir los beneficios que se deducen del consumo de bienes como educación, salud, vivienda, etc., de modo que es esperable que estas políticas sean una herramienta crucial para responder al flujo migratorio. Mientras tanto, la ayuda internacional relaja la restricción presupuestaria de los hogares, expandiendo el consumo privado. Las ganancias agregadas y sectoriales son menores en un escenario donde los migrantes no logran acreditar sus estudios y todo el influjo se incorpora al segmento no calificado del mercado laboral. Además, en dicho escenario, la desigualdad, medida por las brechas salariales de calificación, se incrementa.

Estos hallazgos son consistentes con la evidencia existente sobre los impactos de flujos migratorios masivos y con evaluaciones sobre los impactos del fenómeno migratorio de venezolanos hacia Colombia. Si bien los resultados dependen fuertemente de la modelización y los datos utilizados, pueden ser interpretados como un indicador cualitativo de la dirección y la magnitud de los efectos, y servir como base en el diseño de políticas orientadas a mitigar los efectos adversos y aprovechar las externalidades positivas de la migración. 


\section{Referencias}

Arango L. E., N. Obando y C. E. Posada, (2010). Sensibilidad de los salarios al desempleo regional en Colombia: nuevas estimaciones de la curva de salarios, Borradores de Economía 006829, Banco de la República.

Armington, P. (1969). A theory of demand for products distinguished by place of production. IMF Staff Papers, 16(1), 159 - 176.

Banco Mundial. (2018). Migración desde Venezuela a Colombia: Impactos y Estrategia de Respuesta en el Corto y Mediano Plazo. World Bank, Colombia. @ ( World Bank.

Blanchflower, D. G. y A. J. Oswald (1994). The Wage Curve. MIT Press. Cambridge, MA.

Blanchflower, D., y Oswald, A. J. (1995). An introduction to the wage curve. Journal of Economic Perspectives, 9(3), 153-167.

Blanchflower, D. G., Oswald, A. J. y Sanfey, P. (1996). Wages, profits, and rent-sharing. Quarterly Journal of Economics, 111(1), 227-251.

Blanchflower D. G., Saleheen J. and Shadforth C. (2007). The impact of recent migration from Eastern Europe on the UK economy. Research paper based on a speech given at the Cambridgeshire Chamber of Commerce, UK, 4 January 2007.

Borjas, G. (2003). The labor demand curve is downward sloping: reexamining the impact of immigration on the labor market. The Quarterly Journal of Economics, 118(4), 1335-74.

Botero J. A. y ANDI (2011). Un modelo de Equilibrio General Computable para Colombia. ANDI-CIDE

Brucker, H. y Koglhaas, M. (2004). International Migration to Germany: A CGE-Analysis of Labour Market Impact, working paper presented at the 7th annual conference on global economic analysis, Washington.

Bussolo, M. y J. Lay (2003). Globalisation and Poverty Changes in Colombia. OECD Development Centre Working Papers, No. 226, OECD Publishing, Paris, https://doi.org/10.1787/652528552076.

Bussolo, M., Roland-Holst, D., y Van der Mensbrugghe, D. (1998). The Technical Specification of Fedesarrollo's Long Run General Equilibrium Model. Serie Documentos de Trabajo, Nro. 4, marzo, Fedesarrollo.

Card, D. (1990). The impact of the Mariel boatlift on the Miami labor market. ILR Review, 43(2), 245-257.

Card, D. (1995). The wage curve: a review. Journal of Economic Literature, 33 (2), 285-299.

Caruso G., C. Gomez Canon y V. Mueller (2019). Spillover effects of the Venezuelan crisis: migration impacts in Colombia, Oxford Economic Papers, gpz072.

Cicowiez, M. (2019). Una Matriz de Contabilidad para Colombia 2016. Unpublished. 
Correa Giraldo M. y J. A. Botero García (2018), Fiscal Policy and Inequality in a CGE Model for Colombia, Presented at the 21st Annual Conference on Global Economic Analysis, Cartagena, Colombia.

Devarajan, S. y S. Robinson, (2005). The influence of Computable General Equilibrium Models on Policy. In T. Kehoe, T. Srinivasan y J. Whalley (eds.), Frontiers in Applied General Equilibrium Modeling. Cambridge, MA: Cambridge University Press.

Dustman C., Fabri F. y Preston I. (2005). The impact of immigration on the British labour market. Economic Journal, 115(507), F324-F341.

Dustmann, C., Glitz, A. y Frattini, T. (2008). The labour market impact of immigration. Oxford Review of Economic Policy, 24(3) 477-494.

Dustmann, C., Frattini, T., Halls, C. (2010). Assessing the Fiscal Costs and Benefits of A8 Migration to the UK. Fiscal Studies, 31(1), 1-41.

Escobar-Espinoza, A. A., Guevara-Castañeda, D. A., y Uribe-Veloza, M. A. (2017). Modelos Computacionales y Análisis de la Política Económica en Colombia. Panorama Económico, 25(4), 535-558.

Filipski, Mateusz J.; Tiburcio, Ernesto; Dorosh, Paul A.; Hoddinott, John F.; y Rosenbach, Gracie. (2019). Modelling the economic impact of the Rohingya Influx in Southern Bangladesh. IFPRI Discussion Paper 1819. Washington, DC: International Food Policy Research Institute (IFPRI).

Galiani, S., Cruces, G., Acosta, P. y Gasparini, L., (2017). Educational Upgrading and Returns to Skills in Latin America: Evidence from a Supply-Demand Framework. Working Paper 24015, National Bureau of Economic Research.

Gedan, B. N. (2017). Venezuelan Migration: Is the Western Hemisphere Prepared for a Refugee Crisis?. SAIS review of International Affairs, 37(2), 57-64

Gott, C. y Johnston, K. (2002), The Migrant Population in the UK: Fiscal Effects, Home Office Research, Development and Statistics Directorate, Occasional Paper no. 77, London: Home Office.

Gracia O. y Zuleta H. (2005). "The Free Trade Agreement between Colombia and USA: What can happen to Colombia?" DEGIT Conference Papers c010_023, DEGIT, Dynamics, Economic Growth, and International Trade.

Griliches, ZvI (1969). Capital-Skill Complementarity. Review of Economics and Statistics, 51(4), 465-468.

Hernández, G., Prada, S., y Ramírez, J.M. (2001). Impacto Económico del programa de Desarrollo Alternativo del Plan Colombia. Archivos de Macroeconomía, Departamento Nacional de Planeación.

Hernández, G. (2013). Una reseña de los efectos del Tratado de Libre Comercio entre Colombia y Estados Unidos. Archivos de Economía 011204, Departamento Nacional de Planeación 
Human Rights Watch. (2019). Venezuela events of 2018. World report 2019. New York, NY: Author. Disponible en: https://www.hrw.org/world-report/2019/country-chapters/venezuela

Kerr P. S. y Kerr W. R., (2011). Economic Impacts of Immigration: A Survey. NBER Working Papers 16736, National Bureau of Economic Research, Inc.

Kerr, S. P. y Kerr, W. R. (2016). Immigrants Play a Disproportionate Role in American Entrepreneurship. Harvard Business Review.

Krugman P. R., M. Obstfeld, and M. J. Melitz (2018). International Economics: Theory and Policy. Eleventh Edition, Global Edition, Pearson Education Limited 2018, ISBN 10: 1-29221487-2, SBN 13: 978-1-292-21487-0.

Krusell, P., Ohanian, L. E., Ríos-Rull, J. V. y Violante, G. L. (2000). Capital-Skill Complementarity and Inequality: A Macroeconomic Analysis. Econometrica, 68(5), 10291053.

Lemos, S., y Portes, J. (2008). New Labour? The Impact of Migration from Central and Eastern European Countries on the UK Labour Market, IZA Discussion Paper No. 3756.

Light, M., y T. Rutherford (2002). A General Equilibrium Model for Tax Policy Analysis in Colombia: The MEGATAX Model. Archivos de Economía 011291, Departamento Nacional de Planeación.

Light, M., y T. Rutherford (2003). Free Trade Area of the Americas. An impact assesment for Colombia. Departamento Nacional de Planeación- Archivos de Economía, 222.

Lofgren, H., R. Harris y S. Robinson (2002). A standard computable general equilibrium model (CGE) in GAMS.

Longhi, S., Nijkamp, P. y Poot, J. (2005). A meta-analytic assessment of the effect of immigration on wages. Journal of economic surveys, 19(3), 451-477.

López, Enrique; Ripoll, Marla; y Cepeda, Freddy. (1994). Crónicas de los Modelos de Equilibrio General en Colombia. Borradores Semanales de Economía. No. 13. Banco de la República (diciembre 1994); 65 p.

Manacorda, M., Sánchez-Páramo, C. y Schady, N. (2010). Changes in Returns to Education in Latin America: The Role of Demand and Supply of Skills. Industrial and Labor Relations Review, 63(2), 307-326.

Martín, C. P., y Ramírez, J. M. (2004). El impacto económico de un acuerdo parcial de libre comercio entre Colombia y Estados Unidos (Borradores de Economía No. 326) (p. 41). Banco de la República de Colombia.

Maystadt, J.F., Hirvonen, K., Mabiso, A. y Vandercasteelen, J., (2019). Impacts of Hosting Forced Migrants in Poor Countries. Annual Review of Resource Economics, 11, 439-459.

Medina, C. y Posso, C. (2018). Cambio técnico y polarización en el mercado laboral. Evidencia para Colombia. El trimestre económico, 85(338), 365-410.

Migración Colombia (2020). Más de un millón setecientos setenta y un mil venezolanos están radicados en Colombia, en: Comunicado Oficial de Migración Colombia (25 febrero 2020). 
OECD y ILO. (2018). How Immigrants Contribute to Developing Countries' Economies. OECD.

Ottaviano, G. y Peri, G. (2012). Rethinking the effects of immigration on wages. Journal of the European Economic Association, 10(1), 152-97.

Parro, F. (2013). Capital-Skill Complementarity and the Skill Premium in a Quantitative Model of Trade. American Economic Journal: Macroeconomics, 5(2), 72-117.

Peñaloza Pacheco L., (2019). Living with the Neighbors: The Effect of Venezuelan Forced Migration on Wages in Colombia. CEDLAS, Working Papers 0248, CEDLAS, Universidad Nacional de La Plata.

Perdomo Strauch A. A., (2008). Modelo Estándar de Equilibrio General Computable. Archivos de Economía 004943, Departamento Nacional de Planeación.

Pinzón Piedrahita A. M. (2015). Desarrollo de un modelo de Equilibrio General Computable (MEGC) para analizar las políticas agropecuarias en Colombia. Maestría thesis, Universidad Nacional de Colombia.

Pouliakas, K., Roberts, D., Balamou, E., y Psaltopoulos, D. (2014). Modelling the effects of immigration on regional economic performance and wage distribution: A Computable General Equilibrium (CGE) analysis of three European Union regions. Regional Studies, 48(2), 318338.

Ruiz Mirabal Y. (2018). Hoping to Return Home: The Face of Venezuelan Migrants Crossing the Border to Colombia. University of Texas at Austin.

Ruiz, I. y Vargas-Silva, C. (2013). The economics of forced migration. Journal of Development Studies, 49(6), 772-84.

Sanchez-Martinez Miguel y K. Lisenkova, (2013). The Long Term Economic Impacts of Reducing Migration: The Case of the UK Migration Policy. National Institute of Economic and Social Research (NIESR) Discussion Papers 420, National Institute of Economic and Social Research.

Sánchez, F. y J. J. Núñez (1998). La curva de salarios para Colombia. Estimaciones de las relaciones entre desempleo, la inflación y los ingresos laborales 1984-1996. Archivos de Macroeconomía, núm. 80, DNP, marzo.

Socio-Economic Database for Latin America and the Caribbean (CEDLAS y The World Bank). Fecha de consulta: junio de 2020.

Selee, Andrew, Jessica Bolter, Betilde Muñoz-Pogossian, and Miryam Hazán (2019). Creativity amid Crisis: Legal Pathways for Venezuelan Migrants in Latin America. January 2019.

Shapiro, C., y Stiglitz, J. E. (1984). Equilibrium unemployment as a worker discipline device. The American Economic Review, 74(3), 433-444. 
Shoven, J. B. y Whalley, J. (1984). Applied general-equilibrium models of taxation and international trade: An introduction and survey. Journal of Economic literature, 22(3), $1007-$ 1051.

Suescún, R. y Steiner, R. (2017). Un modelo de equilibrio general dinámico para la evaluación de la política económica en Colombia. Bogotá: Fedesarrollo, 83 p.

Sussangkarn, C. (1996). Macroeconomic Impacts of Migrant Workers: Analyses with a CGE Model. TDRI Quarterly Review, 11(3), 3-11.

Taylor, J. E., Filipski, M.J., Alloush, M., Gupta, A., Rojas Valdes, R.I., y Gonzalez-Estrada, E. (2016). Economic impact of refugees. Proceedings of the National Academy of Sciences, 113(27), 7449-7453. doi:10.1073/pnas.1604566113.

United Nations Refugee Agency and International Organization for Migration (2019). Regional Refugee and Migrant Response Plan for Refugees and Migrants from Venezuela (Geneva: United Nations Refugee Agency and International Organization for Migration).

United Nations High Commissioner for Refugees (UNHCR) (2019). Refugees and migrants from Venezuela top 4 million: UNHCR and IOM. Geneva, Switzerland.

Vaughan Caro, D. (2005). Tratado de Libre Comercio y Barreras No Arancelarias: Un análisis crítico. Archivos de Economía 003657, Departamento Nacional de Planeación

Venables, A. (1999). Trade liberalisation and factor mobility: an overview. In: Faini R., DeMelo J. and Zimmermann K.F. (eds.), Migration. The Controversies and the Evidence (pp. 23-48) Cambridge University Press: Cambridge, MA,.

Vera, L. (2015). Venezuela 1999-2014: macro-policy, oil governance and economic performance. Comparative Economic Studies, 56(3), 539-69. 
Apéndice A. Hechos estilizados.

Tabla A.1. Inmigrantes en Colombia, por origen (porcentaje y total anual)

\begin{tabular}{cccc}
\multicolumn{4}{c}{ Hace 1 año vivían en } \\
\hline Año & Venezuela & Resto & Total \\
\hline 2014 & 38.40 & 61.60 & 119,291 \\
2015 & 53.78 & 46.22 & 149,162 \\
2016 & 69.60 & 30.40 & 247,607 \\
2017 & 79.39 & 20.61 & 365,154 \\
2018 & 90.23 & 9.77 & 751,703 \\
2019 & 90.74 & 9.26 & 845,896 \\
\hline
\end{tabular}

Fuente: Elaboración propia en base a GEIH (DANE).

Notas: Se utilizaron ponderadores muestrales. En "Resto" se incluyen EEUU, España, Ecuador, Panamá, Perú, Costa Rica, Argentina, Francia, Italia y otros.

Figura A.1. Migrantes desde Venezuela hacia Colombia, por nacionalidad, 2014-2019

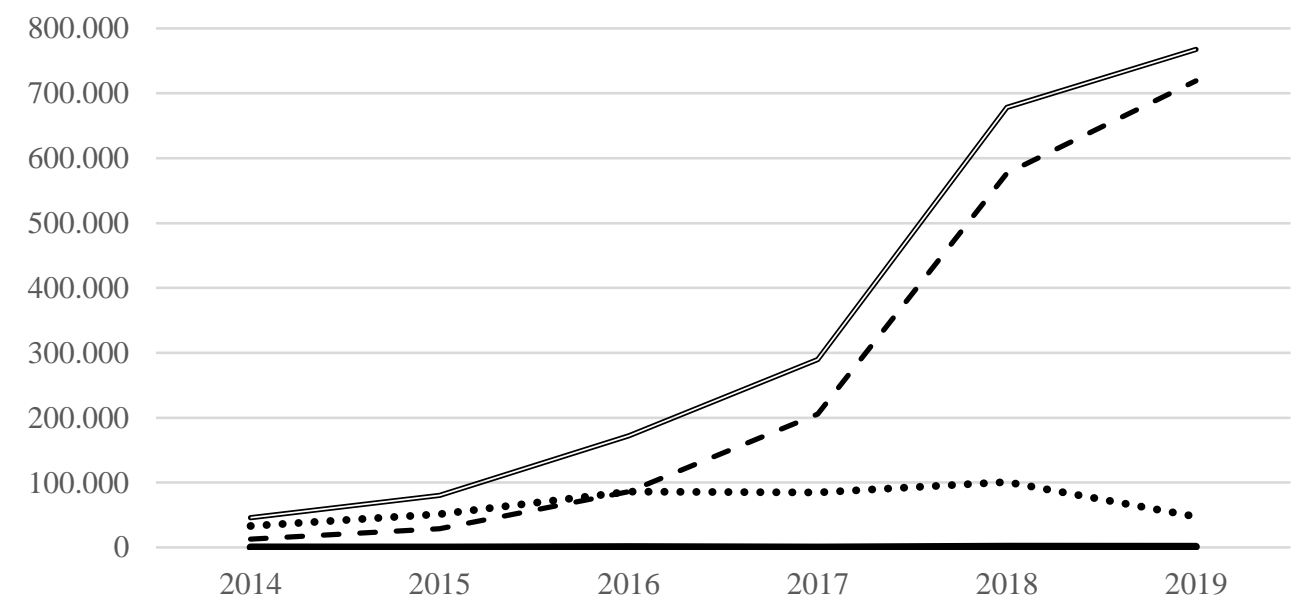

Fuente: Elaboración Propia en base a GEIH (DANE).

Notas: Se utilizaron ponderadores muestrales. Individuos en Colombia que hace 12 meses vivían en Venezuela. Referencias: Línea doble = "total"; línea discontinua = "venezolano"; línea punteada = "colombiano"; línea sólida = "otros". 
Tabla A.2. Migrantes venezolanos (total y \% activo), por nivel de calificación, 2014-2019

\begin{tabular}{ccccccccc}
\hline \multirow{2}{*}{ Año } & \multicolumn{2}{c}{ No calificados } & \multicolumn{2}{c}{ Semi-calificados } & \multicolumn{2}{c}{ Calificados } & \multirow{2}{*}{ Total } & \multirow{2}{*}{ \% Activo } \\
& Total & \% Activo & Total & \% Activo & Total & \% Activo & & \\
\hline 2014 & 2,609 & 70.45 & 2,597 & 74.09 & 413 & 53.75 & 5,619 & 70.90 \\
2015 & 4,441 & 54.11 & 4,273 & 66.51 & 2,674 & 80.03 & 11,388 & 64.85 \\
2016 & 17,825 & 62.80 & 21,516 & 78.37 & 6,689 & 96.13 & 46,030 & 74.92 \\
2017 & 41,229 & 70.55 & 65,441 & 86.83 & 16,084 & 90.64 & 122,754 & 81.86 \\
2018 & 135,000 & 75.67 & 205,187 & 88.99 & 46,377 & 88.13 & 386,564 & 84.23 \\
2019 & 187,237 & 72.58 & 233,698 & 81.65 & 48,898 & 84.67 & 469,833 & 78.35 \\
\hline
\end{tabular}

Fuente: Elaboración propia en base a GEIH (DANE).

Notas: Se utilizaron ponderadores muestrales. Se define migrante a aquel individuo que se trasladó desde Venezuela hacia Colombia en los 12 meses previos. Se define no calificado (semi-calificados) a aquel individuo cuyo máximo nivel educativo alcanzado es menor que secundaria (superior) completa, mientras calificado es aquel con educación superior completa. Se restringen los cálculos a la población en edad de trabajar (de entre 15 y 64 años de edad).

Tabla A.3. Nivel de calificación en la PEA: migrantes venezolanos vs. Residentes colombianos

\begin{tabular}{ccccccccc}
\hline & \multicolumn{3}{c}{ Migrantes venezolanos } & \multicolumn{5}{c}{ Residentes Colombianos } \\
Año & No calificados Semi-calificados & Calificados & Total & No calificados Semi-calificados & Calificados & Total \\
\hline 2014 & 46.13 & 48.29 & 5.57 & 100 & 47.61 & 38.53 & 13.86 & 100 \\
2015 & 32.54 & 38.48 & 28.98 & 100 & 46.82 & 39.85 & 13.33 & 100 \\
2016 & 32.46 & 48.90 & 18.65 & 100 & 42.75 & 43.06 & 14.19 & 100 \\
2017 & 28.94 & 56.55 & 14.51 & 100 & 41.77 & 43.90 & 14.33 & 100 \\
2018 & 31.37 & 56.08 & 12.55 & 100 & 40.52 & 44.79 & 14.68 & 100 \\
2019 & 36.92 & 51.84 & 11.25 & 100 & 39.09 & 45.66 & 15.25 & 100 \\
\hline
\end{tabular}

Fuente: Elaboración propia en base a GEIH (DANE).

Notas: Se utilizaron ponderadores muestrales. Se define migrante a aquel individuo que se trasladó desde Venezuela hacia Colombia en los 12 meses previos. Se define no calificado (semi-calificados) a aquel individuo cuyo máximo nivel educativo alcanzado es menor que secundaria (superior) completa, mientras calificado es aquel con educación superior completa. Se restringen los cálculos a la población en edad de trabajar (de entre 15 y 64 años de edad) y que participan activamente en el mercado laboral. 
Tabla A.4. Comparación de medias entre migrantes venezolanos y nativos

\begin{tabular}{|c|c|c|c|}
\hline & $\begin{array}{c}\text { Migrantes Venezolanos } \\
\text { (1) } \\
\text { Media } \\
\end{array}$ & $\begin{array}{l}\text { Nativos } \\
\text { (2) } \\
\text { Media } \\
\end{array}$ & $\begin{array}{c}(1)-(2) \\
\text { Coef/p-valor }\end{array}$ \\
\hline \multicolumn{4}{|l|}{ Panel A: 2014-2019 } \\
\hline PEA & 0.8058 & 0.7436 & $\begin{array}{c}0.0622 \\
(0.0000)\end{array}$ \\
\hline No calificado (PEA) & 0.336 & 0.4226 & $\begin{array}{l}-0.0866 \\
(0.0000)\end{array}$ \\
\hline Semi-calificado (PEA) & 0.5373 & 0.4332 & $\begin{array}{c}0.1041 \\
(0.0000)\end{array}$ \\
\hline Calificado (PEA) & 0.1256 & 0.1441 & $\begin{array}{c}-0.0185 \\
(0.0000) \\
\end{array}$ \\
\hline \multicolumn{4}{|l|}{ Panel B: 2016-2019 } \\
\hline PEA & 0.8084 & 0.7368 & $\begin{array}{c}0.0716 \\
(0.0000)\end{array}$ \\
\hline No calificado (PEA) & 0.3358 & 0.4104 & $\begin{array}{l}-0.0746 \\
(0.0000)\end{array}$ \\
\hline Semi-calificado (PEA) & 0.5394 & 0.4434 & $\begin{array}{c}0.0960 \\
(0.0000)\end{array}$ \\
\hline Calificado (PEA) & 0.1246 & 0.1461 & $\begin{array}{l}-0.0215 \\
(0.0000) \\
\end{array}$ \\
\hline
\end{tabular}

Fuente: Elaboración propia en base a GEIH (DANE).

Notas: Se utilizaron ponderadores muestrales. Se define migrante a aquel individuo que se trasladó desde Venezuela hacia Colombia en los 12 meses previos. Se define no calificado (semi-calificados) a aquel individuo cuyo máximo nivel educativo alcanzado es menor que secundaria (superior) completa, mientras calificado es aquel con educación superior completa. Se restringen los cálculos a la población en edad de trabajar (de entre 15 y 64 años de edad). Las medias reportadas en esta tabla corresponden a los coeficientes estimados de una regresión de la variable de interés (nivel de actividad o nivel de calificación) en una variable indicadora que vale uno para migrantes venezolanos y cero para los nativos. Entre paréntesis se reporta el p-valor. 
Tabla A.5. Evolución de la PEA e inmigrantes venezolanos activos

\begin{tabular}{|c|c|c|c|c|c|}
\hline \multirow[b]{2}{*}{ Año } & \multirow[b]{2}{*}{ Total PEA } & \multicolumn{4}{|c|}{ Migrantes venezolanos } \\
\hline & & No calificados & $\begin{array}{c}\text { Semi } \\
\text { calificados }\end{array}$ & Calificados & Total \\
\hline 2014 & $22,335,752$ & 1,838 & 1,924 & 222 & 3,984 \\
\hline 2015 & $22,824,228$ & 2,403 & 2,842 & 2,140 & 7,385 \\
\hline 2016 & $23,021,692$ & 11,194 & 16,862 & 6,430 & 34,486 \\
\hline 2017 & $23,288,292$ & 29,085 & 56,823 & 14,578 & 100,486 \\
\hline 2018 & $23,498,968$ & 102,151 & 182,599 & 40,871 & 325,621 \\
\hline 2019 & $23,491,372$ & 135,888 & 190,819 & 41,400 & 368,107 \\
\hline \multicolumn{2}{|c|}{ Acumulado 17-19 } & 267,124 & 430,241 & 96,849 & 794,214 \\
\hline \multicolumn{2}{|c|}{$\%$ Total Acumulado } & 33.63 & 54.17 & 12.19 & 100.00 \\
\hline \multicolumn{2}{|c|}{$\%$ PEA 2016 con $=$ calificación } & 2.72 & 4.34 & 2.94 & 3.45 \\
\hline
\end{tabular}

Fuente: Elaboración propia en base a GEIH (DANE).

Notas: Se utilizaron ponderadores muestrales. Se define migrante a aquel individuo que se trasladó desde Venezuela hacia Colombia en los 12 meses previos. Se define no calificado (semi-calificados) a aquel individuo cuyo máximo nivel educativo alcanzado es menor que secundaria (superior) completa, mientras calificado es aquel con educación superior completa. Se restringen los cálculos a la población en edad de trabajar (de entre 15 y 64 años de edad).

Figura A.2. Producto Bruto Interno, Colombia, 2010-2018. en miles de millones de pesos constantes de 2015 (eje izquierdo) y variación interanual (eje derecho)

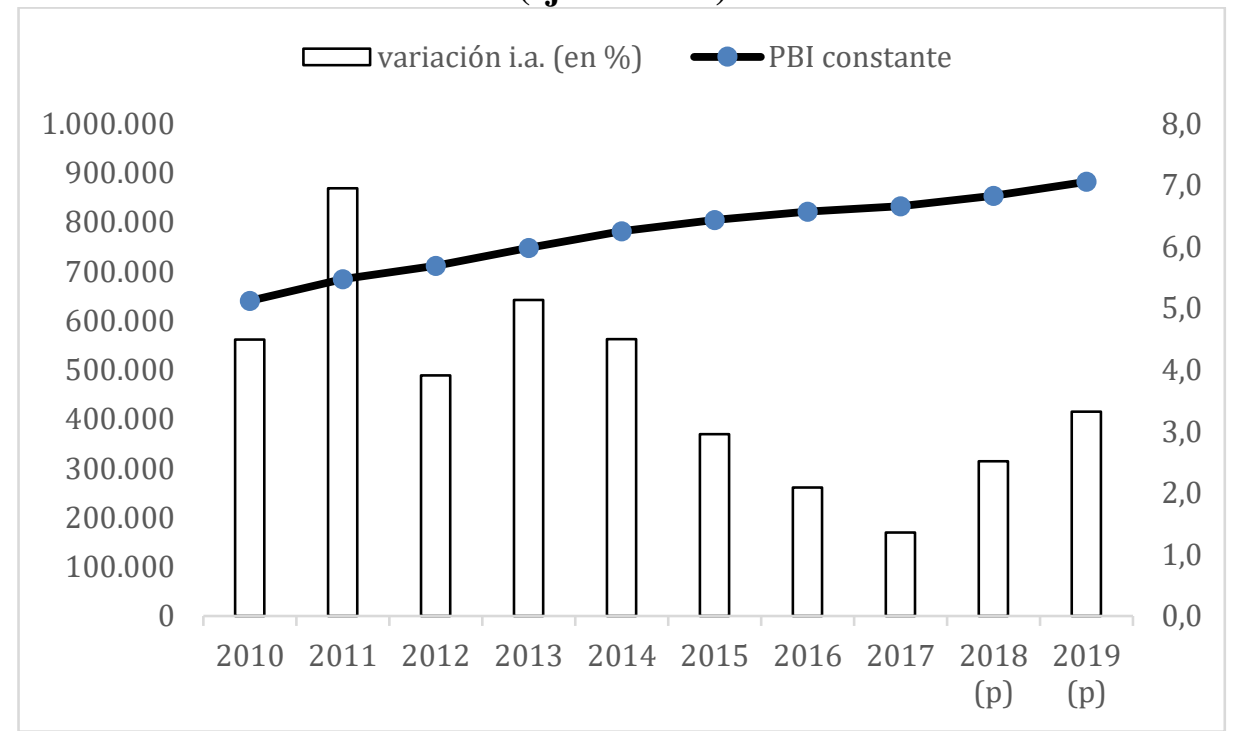

Fuente: Elaboración Propia en base a DANE. Datos de 2019 y 2019 son provisorios. 
Tabla A.6. Tasas de desempleo, por nivel de calificación. Total Colombia y en población de venezolanos

\begin{tabular}{|c|c|c|c|c|c|c|c|c|}
\hline & & Total Co & ombia & & & Venez & lanos & \\
\hline Año & $\begin{array}{c}\text { No } \\
\text { calificados }\end{array}$ & $\begin{array}{c}\text { Semi- } \\
\text { calificados }\end{array}$ & Calificados & Total & $\begin{array}{c}\text { No } \\
\text { calificados }\end{array}$ & $\begin{array}{c}\text { Semi- } \\
\text { calificados }\end{array}$ & Calificados & Total \\
\hline 2014 & 7.64 & 11.88 & 7.82 & 9.39 & 8.83 & 14.14 & 12.08 & 12.00 \\
\hline 2015 & 7.32 & 11.54 & 8.10 & 9.19 & 11.39 & 10.26 & 9.48 & 10.40 \\
\hline 2016 & 7.28 & 11.78 & 9.52 & 9.54 & 13.87 & 17.43 & 11.28 & 14.97 \\
\hline 2017 & 7.35 & 12.19 & 9.07 & 9.72 & 11.82 & 16.92 & 12.76 & 14.68 \\
\hline 2018 & 7.53 & 12.41 & 9.46 & 10.01 & 12.96 & 15.89 & 13.77 & 14.66 \\
\hline 2019 & 8.55 & 12.74 & 9.83 & 10.67 & 15.46 & 14.88 & 12.84 & 14.80 \\
\hline Prome & dio $14-19$ & & & & 17.84 & 20.10 & 19.30 & 19.22 \\
\hline Venez & olanos vs Re & sidentes & & & 10.32 & 8.20 & 10.25 & 9.58 \\
\hline p-valor & & & & & $(0.00)$ & $(0.00)$ & $(0.00)$ & $(0.00)$ \\
\hline Prome & dio $16-19$ & & & & 17.87 & 20.17 & 19.31 & 19.29 \\
\hline Venez & olanos vs Re & sidentes & & & 10.32 & 7.97 & 9.88 & 9.40 \\
\hline p-valo & & & & & $(0.00)$ & $(0.00)$ & $(0.00)$ & $(0.00)$ \\
\hline
\end{tabular}

Fuente: Elaboración propia en base a GEIH (DANE).

Notas: Se utilizaron ponderadores muestrales. Se define no calificado (semi-calificados) a aquel individuo cuyo máximo nivel educativo alcanzado es menor que secundaria (superior) completa, mientras calificado es aquel con educación superior completa. Se restringen los cálculos a la población en edad de trabajar (de entre 15 y 64 años de edad). La tasa de desempleo se computa para la submuestra que participa activamente en el mercado laboral. Venezolanos refiere a aquellos nacidos en Venezuela. Las medias reportadas en esta tabla corresponden a los coeficientes estimados de una regresión de la variable de interés (desempleo) en una variable indicadora que vale uno para migrantes venezolanos y cero para los nativos. Entre paréntesis se reporta el p-valor. 


\section{Apéndice B. Formulación matemática del modelo de CGE}

En este apéndice se presenta la formulación matemática del modelo de CGE utilizado. Para un detalle completo ver Lofgren et al. (2002). En las Tablas B.1-B.4 se explican los principios de notación y se definen los sets, las variables y los parámetros del modelo. Luego, se explicitan las ecuaciones del modelo divididas en cuatro bloques: A. Actividades de producción y mercados de factores; B. Comercio Doméstico e Internacional; C. Instituciones Domésticas; y D. Restricciones del sistema e índices de precios.

Tabla B.1. Principios notacionales

\begin{tabular}{|l|l|}
\hline \multicolumn{1}{|c|}{ Item } & \multicolumn{1}{c|}{ Notación } \\
\hline Set & Letra minúscula latina como subíndice de variables y parámetros. \\
\hline Variable Endógena & Letra mayúscula latina (sin una barra) \\
\hline Variable Exógena & Letra mayúscula latina con una barra \\
\hline Parámetro & Letra minúscula latina o griega (con o sin subíndice) \\
\hline
\end{tabular}

Tabla B.2. Sets

\begin{tabular}{|c|c|c|}
\hline Nombre & Descripción & \\
\hline$a \in A$ & $\begin{array}{lr}\text { Actividades } & \text { (sectores } \\
\text { productivos } & \mathrm{O} \\
\text { industrias) } & \\
\end{array}$ & $\begin{array}{l}A=\{\mathrm{a}-\text { agr, } \mathrm{a}-\min , \mathrm{a}-\text { food, } \mathrm{a}-\text { refpet, } \mathrm{a}- \\
\text { maq, a - othmnfc, } \mathrm{a}-\text { othind, } \mathrm{a}-\operatorname{trdtrns}, \mathrm{a}- \\
\text { admpub, } \mathrm{a}-\text { othsvc }\}\end{array}$ \\
\hline$c \in C$ & Bienes (y servicios) & $\begin{array}{l}C=\{c-\text { agr, } c-\min , c-\text { food, } c-\text { refpet, } c- \\
\text { maq, } c-\text { othmnfc, } c-\text { othind, } c-\text { trdtrns, } c- \\
\text { admpub, } c-\text { othsvc }\}\end{array}$ \\
\hline$l a b \in L A B$ & $\begin{array}{l}\text { Categorías de factor } \\
\text { trabajo según nivel de } \\
\text { calificación }\end{array}$ & $L A B=\{$ nocal, semical, cal $\}$ \\
\hline ins $\epsilon$ INS & Instituciones & $I N S=\{$ hhd, gov, row $\}$ \\
\hline
\end{tabular}


Tabla B.3. Variables

\begin{tabular}{|c|c|}
\hline Nombre & Descripción \\
\hline CPI & Índice de precios al consumidor \\
\hline$D P I$ & Índice de precios al productor \\
\hline$E G$ & Gasto Público Corriente Total \\
\hline EXR & Tipo de Cambio (moneda local por unidad de moneda extranjera) \\
\hline$K D_{a}$ & Cantidad de Factor Capital demandada por la actividad $a$ \\
\hline$K S_{a}$ & Cantidad de Factor Capital ofertada a la actividad $a$ \\
\hline$L D_{l a b, a}$ & Cantidad de la categoría $l a b$ del Factor Trabajo demandada por la actividad $a$ \\
\hline$L S_{l a b}$ & Cantidad ofertada de la categoría lab del Factor Trabajo \\
\hline$M P S$ & Propensión marginal a ahorrar de los hogares \\
\hline MPSSCAL & Factor de escala de $M P S$ \\
\hline$P A_{a}$ & Precio del producto de la actividad $a$ \\
\hline$P B D_{a}$ & Precio del compuesto factorial $B D$ de la actividad $a$ \\
\hline$P H D_{a}$ & Precio del compuesto factorial $H D$ de la actividad $a$ \\
\hline$P D_{c}$ & Precio del bien $c$ vendido domésticamente \\
\hline$P E_{c}$ & Precio de exportación del bien $c$ (moneda doméstica) \\
\hline$P M_{c}$ & Precio de importación del bien $c$ (moneda doméstica) \\
\hline$P Q_{c}$ & Precio del bien compuesto $c$ \\
\hline$P V A_{a}$ & Precio del Valor Agregado de la actividad $a$ \\
\hline$P X_{c}$ & Precio al productor del bien $c$ \\
\hline$Q A_{a}$ & Nivel de actividad de $a$ \\
\hline$Q D_{c}$ & Cantidad vendida domésticamente del producto doméstico $c$ \\
\hline$Q E_{c}$ & Cantidad exportada del bien $c$ \\
\hline$Q G_{c}$ & Cantidad del bien $c$ demandada por el Gobierno \\
\hline QGSCAL & Factor de escala para el gasto del Gobierno \\
\hline$S A V G$ & Ahorro del Gobierno \\
\hline SAVGREAL & Ahorro del Gobierno en términos reales \\
\hline$S A V F$ & Ahorro externo (en moneda extranjera) \\
\hline SAVFSCAL & Factor de escala para el Ahorro externo (en moneda extranjera) \\
\hline$Q H_{c}$ & Cantidad del bien $c$ consumida por los hogares \\
\hline$Q I N T_{c, a}$ & Cantidad del bien $c$ utilizada como insumo intermedio en la actividad $a$ \\
\hline$Q I N V_{c}$ & Cantidad del bien $c$ demandada para inversión \\
\hline QINVSCAL & Factor de escala para la inversión (formación de capital fijo) \\
\hline$Q M_{c}$ & Cantidad importada del bien $c$ \\
\hline$Q Q_{c}$ & Cantidad del bien $c$ ofertada domésticamente \\
\hline$Q X_{c}$ & Cantidad del bien $c$ producida domésticamente \\
\hline$W K_{a}$ & Remuneración al Factor Capital en la actividad $a$ \\
\hline$W L_{l a b}$ & Remuneración a la categoría lab del Factor Trabajo \\
\hline$U E R A T_{l a b}$ & Tasa de Desempleo de la categoría lab del Factor Trabajo \\
\hline$Y G$ & Ingreso del Gobierno \\
\hline$Y H$ & Ingreso de los Hogares \\
\hline$Y K$ & Ingreso del Factor Capital \\
\hline$Y L$ & Ingreso del Factor Trabajo \\
\hline REXR & Tipo de Cambio Real \\
\hline WALRAS & Ley de Walras \\
\hline
\end{tabular}


Tabla B.4. Parámetros/Variables exógenas

\begin{tabular}{|c|c|}
\hline Nombre & Descripción \\
\hline$q d s t k_{c}$ & Cambio en inventarios \\
\hline$q i n v b_{C}$ & Cantidad del bien $c$ demandada para inversión en el año base \\
\hline$q g b_{c}$ & Cantidad del bien $c$ demandada por el Gobierno en el año base \\
\hline$m p s$ & Propensión marginal (y media) a ahorrar de los hogares \\
\hline$s a v f b$ & Ahorro externo (en moneda extranjera) en el año base \\
\hline$t a_{a}$ & Tasa impositiva sobre el valor bruto del producto de la actividad $a$ \\
\hline$t e_{c}$ & Tasa de subsidio a la exportación del bien $c$ \\
\hline$t m_{c}$ & Tasa de impuesto a la importación del bien $c$ \\
\hline$t q_{c}$ & Tasa de impuesto a las ventas del bien $c$ \\
\hline ty & Tasa impositiva al ingreso de los hogares \\
\hline$q g_{c}$ & Demanda del gobierno del bien $c$ \\
\hline $\operatorname{trnsfr}(a c, i n s)$ & Transferencia de la institución ins a la institución o factor $a c$ \\
\hline$p w e_{c}$ & Precio de exportación del bien $c$ (moneda extranjera) \\
\hline$p w m_{c}$ & Precio de importación del bien $c$ (moneda extranjera) \\
\hline$\delta_{a}^{j}$ & $\begin{array}{l}\text { participación del compuesto factorial } j \in J=\{B D, H D\} \text { en el valor agregado de la } \\
\text { actividad } a\end{array}$ \\
\hline$\delta_{a}^{j, f}$ & $\begin{array}{l}\text { es la participación del factor de producción } f \epsilon F=\left\{K D, L D_{l}\right\} \text { en el compuesto } \\
\text { factorial } j \text { del valor agregado de la actividad } a\end{array}$ \\
\hline$\varphi_{a}^{\mathrm{VA}}$ & es un parámetro de eficiencia de la función de producción de la actividad $a$ \\
\hline$\rho_{a}^{j}$ & $\begin{array}{l}\text { parámetro relacionado con la elasticidad de sustitución del agregado } j \text { del valor } \\
\text { agregado de la actividad } a\end{array}$ \\
\hline$\sigma_{a}^{V A}$ & elasticidad de sustitución del VA de la actividad $a$ \\
\hline$\sigma_{a}^{j}$ & $\begin{array}{l}\text { elasticidad de sustitución del agregado } j \epsilon J=\{B D, H D\} \text { del valor agregado de la } \\
\text { actividad } a\end{array}$ \\
\hline$\theta_{a, c}$ & Rendimiento de producto $c$ por unidad de la actividad $a$ \\
\hline$i c a_{c, a}$ & Cantidad de bien $c$ utilizada como insumo intermedio por unidad de la actividad $a$ \\
\hline$\alpha_{c}$ & Participación del bien $c$ en el consumo de los hogares \\
\hline$\delta_{c}^{\mathrm{m}}$ & Parámetro de participación de las importaciones del bien $c$ de la función Armington \\
\hline$\delta_{c}^{d d}$ & Parámetro de participación doméstica del bien $c$ de la función Armington \\
\hline$\varphi_{c}^{\mathrm{q}}$ & Parámetro de traslación de la función Armington para el bien $c$ \\
\hline$\sigma_{c}^{\mathrm{q}}$ & Elasticidad de sustitución entre bienes domésticos e importaciones para el bien $c$ \\
\hline$\rho_{c}^{q}$ & Exponente de la función Armington para el bien $c$ \\
\hline$\delta_{c}^{e}$ & Parámetro de participación en la función CET de las exportaciones del bien $c$ \\
\hline$\delta_{c}^{d s}$ & Parámetro de participación en la función CET del bien doméstico $c$ \\
\hline$\varphi_{c}^{\mathrm{X}}$ & Parámetro de traslación de la función CET para el bien $c$ \\
\hline$\sigma_{c}^{\mathrm{X}}$ & $\begin{array}{l}\text { Elasticidad de transformación entre ventas domésticas y exportaciones para el bien } \\
c\end{array}$ \\
\hline$\rho_{c}^{x}$ & Exponente de la función CET para el bien $c$ \\
\hline$c t w S_{C}$ & Ponderador del bien $c$ en el $C P I$ \\
\hline$\eta_{l}$ & $\begin{array}{l}\text { Elasticidad del salario real de la categoría de trabajo } l \text { respecto al nivel de desempleo } \\
\text { de la categoría de trabajo } l\end{array}$ \\
\hline
\end{tabular}


B.1. Actividades de Producción y mercados de factores:

B.1.1. Valor agregado y compuestos factoriales

$$
\begin{aligned}
& Q A_{a}=\varphi_{a}^{\mathrm{VA}}\left(\delta_{a}^{\mathrm{BD}} B D_{a}^{-\rho_{a}^{\mathrm{VA}}}+\delta_{a}^{\mathrm{HD}} H D_{a}^{-\rho_{a}^{\mathrm{VA}}}\right)^{-\frac{1}{\rho_{a}^{\mathrm{VA}}}} \quad \sigma_{a}^{\mathrm{VA}}=\frac{1}{1+\rho_{a}^{\mathrm{VA}}} \quad a \in A \\
& B D_{a}=\left(\frac{P V A_{a}}{P B D_{a}}\right)^{\sigma_{a}^{\mathrm{VA}}} \delta_{a}^{\mathrm{BD}} \sigma_{a}^{\mathrm{VA}} \varphi_{a}^{\mathrm{VA}} \sigma_{a}^{\mathrm{VA}-1} Q A_{a} \quad \sigma_{a}^{\mathrm{BD}}=\frac{1}{1+\boldsymbol{\rho}_{a}^{\mathrm{BD}}} \quad a \in A \\
& H D_{a}=\left(\frac{P V A_{a}}{P H D_{a}}\right)^{\sigma_{a}^{\mathrm{VA}}} \delta_{a}^{\mathrm{HD}} \sigma_{a}^{\mathrm{VA}} \varphi_{a}^{\mathrm{VA}} \sigma_{a}^{\mathrm{VA}}-1 \quad A_{a} \quad \sigma_{a}^{\mathrm{HD}}=\frac{1}{1+\rho_{a}^{\mathrm{HD}}} \quad a \in A
\end{aligned}
$$

\section{B.1.2. Demandas factoriales}

$$
\begin{array}{ll}
L D_{\text {nocal }, a}=\left(\frac{P B D_{a}}{W L_{\text {nocal }}}\right)^{\sigma_{a}^{\mathrm{BD}}} \delta_{a}^{\mathrm{BD}, \mathrm{nocal}} \sigma_{a}^{\mathrm{BD}} \varphi_{a}^{B D^{\sigma_{a}^{\mathrm{BD}}-1} B D_{a}} & a \epsilon A \\
L D_{\text {semi-cal }, a}=\left(\frac{P B D_{a}}{W L_{\text {semi-cal }}}\right)^{\sigma_{a}^{\mathrm{BD}}} \delta_{a}^{\mathrm{BD}, \mathrm{semi}-\mathrm{cal}} \sigma_{a}^{\mathrm{BD}} \varphi_{a}^{B D_{a}^{\mathrm{BD}}-1} B D_{a} & a \epsilon A \\
L D_{c a l, a}=\left(\frac{P H D_{a}}{W L_{c a l}}\right)^{\sigma_{a}^{\mathrm{HD}}} \delta_{a}^{\mathrm{HD}, \mathrm{cal}} \sigma_{a}^{\mathrm{HD}} \varphi_{a}^{H D^{\sigma_{a}^{\mathrm{HD}}}-1} H D_{a} & a \epsilon A \\
\bar{K}_{a}=\left(\frac{P H D_{a}}{W K_{a}}\right)^{\sigma_{a}^{\mathrm{HD}}} \delta_{a}^{\mathrm{HD}, \mathrm{K}} \sigma_{a}^{\mathrm{HD}} \varphi_{a}^{H D^{\sigma_{a}^{\mathrm{HD}}}-1} H D_{a} & a \in A
\end{array}
$$

\section{B.1.3. Demandas de insumos intermedios}

$Q I N T_{c, a}=i c a_{c, a} Q A_{a}$

\section{B.1.4. Producto}

$Q X_{c}=\sum_{a \in A} \theta_{a, c} Q A_{a}$

$c \in C$

\section{B.1.5. Precio del Valor Agregado y de los compuestos factoriales}

$$
\begin{array}{lc}
P V A_{a}=P A_{a}\left(1-t a_{a}\right)-\sum_{c \epsilon C} P Q_{c} i c a_{c, a} & a \in A \\
B D_{a} P B D_{a}=W L_{\text {nocal }} L D_{\text {nocal }, a}+W L_{\text {semi-cal }} L D_{\text {semi-cal }, a} & a \in A \\
H D_{a} P H D_{a}=W L_{\text {cal }} L D_{\text {cal }, a}+W K_{a} \overline{K D}_{a} & a \in A
\end{array}
$$

\section{B.1.6. Precio de la actividad}

$$
P A_{a}=\sum_{c \in C} \theta_{a, c} P X_{c}
$$




\section{B.1.7. Ingreso factorial}

$Y L=\sum_{a \epsilon A} \sum_{l a b \epsilon L A B} W L_{l a b} L D_{l a b, a}+\sum_{l a b \in L A B} t_{r n s f r} r_{l a b, r o w} E X R$

$Y K=\sum_{a \in A} W K_{a} \overline{K D}_{a}+$ trnsfr $_{\text {cap }, \text { row }} E X R$

\section{B.2. Comercio Doméstico e Internacional.}

\section{B.2.1. Precio de exportación}

$P E_{c}=\left(1-t e_{c}\right) E X R p w e_{c}$

$c \in C$

\section{B.2.2. Precio de importación}

$P M_{c}=\left(1+t m_{c}\right) E X R p w m_{c}$

$c \in C$

B.2.3. Oferta compuesta (transables)

$Q Q_{c}=\varphi_{a}^{\mathrm{q}}\left(\delta_{c}^{\mathrm{m}} Q M_{c}^{-\rho_{c}^{q}}+\delta_{c}^{\mathrm{dd}} Q D_{c}^{-\rho_{c}^{q}}\right)^{\frac{-1}{\rho_{c}^{\mathrm{q}}}} \quad \sigma_{a}^{\mathrm{q}}=\frac{1}{1+\rho_{c}^{\mathrm{q}}} \quad c \in C$

\section{B.2.4. Oferta compuesta (no transables)}

$Q Q_{c}=Q M_{c}+Q D_{c}$

$c \in C$

B.2.5. Ratio importaciones sobre demanda doméstica

$\frac{Q M_{c}}{Q D_{c}}=\left(\frac{P D_{c} \delta_{c}^{\mathrm{m}}}{P M_{c} \delta_{c}^{\mathrm{dd}}}\right)^{\sigma_{a}^{\mathrm{q}}}$

$c \in C$

\section{B.2.6. Precio Compuesto}

$P Q_{c} Q Q_{c}=\left(P M_{c} Q M_{c}+P D_{c} Q D_{c}\right)\left(1+t q_{c}\right)$

$c \in C$

B.2.7. Transformación del producto (transables)

$Q X_{c}=\varphi_{c}^{x}\left(\delta_{c}^{\mathrm{e}} Q E_{c}^{\rho_{c}^{x}}+\delta_{c}^{\mathrm{ds}} Q D_{c}^{\rho_{c}^{x}}\right)^{\frac{1}{\rho_{c}^{\mathrm{x}}}} \quad \sigma_{a}^{\mathrm{x}}=\frac{1}{\rho_{c}^{\mathrm{x}}-1} \quad c \in C$ 
B.2.8. Transformación del producto (no transables)

$Q X_{c}=Q E_{c}+Q D_{c} \quad c \in C$

B.2.9. Ratio exportaciones sobre demanda doméstica

$$
\frac{Q E_{c}}{Q D_{c}}=\left(\frac{P E_{c} \delta_{c}^{\mathrm{ds}}}{P D_{c} \delta_{c}^{\mathrm{e}}}\right)^{\sigma_{a}^{\mathrm{x}}}
$$

$c \in C$

B.2.10. Precio del Productor

$P X_{c} Q X_{c}=\left(P E_{c} Q E_{c}+P D_{c} Q D_{c}\right)$

$c \in C$

B.3. Instituciones Domésticas.

B.3.1. Ingreso de los hogares

$Y H=Y L+Y K+t_{r n s f} r_{h h d, g o v} \overline{C P I}+t_{r n s f r_{h h d, r o w}} E X R$

B.3.2. Propensión Marginal a ahorrar de los Hogares

$M P S=m p s b * \overline{M P S S C A L}$

B.3.3. Gasto en Consumo de los Hogares

$Q H_{c}=\frac{\alpha_{c}(1-M P S)\left(1-t_{y}\right) Y H}{P Q_{c}}$

$c \in C$

\section{B.3.4. Ingreso del Gobierno}

$Y G=t_{y} Y H+\sum_{a \in A} t a_{a} P A_{a} Q A_{a}+\sum_{c \in C} t q_{c}\left(P M_{c} Q M_{c}+P D_{c} Q D_{c}\right)+$ $\sum_{c \in C}$ tm $_{c}$ EXRpwm $_{c} Q M_{c}+\sum_{c \in C}$ te $_{c} E_{\text {XRpwe }} Q E_{c}+$ trnsfr $_{\text {gov,row }} E X R$

\section{B.3.5. Demanda de Consumo del Gobierno}

$Q G_{c}=q g b_{c} \overline{Q G S C A L}$

B.3.6. Gasto del Gobierno

$E G=\sum_{c \in C} P Q_{c} Q G_{c}+\operatorname{trnsfr}_{h d d, g o v} \overline{C P I}$ 


\section{B.3.7. Ahorro del Gobierno}

$S A V G=Y G-E G$
$S A V G R E A L=\frac{\text { SAVG }}{\overline{C P I}}$

B.4. Condiciones de equilibrio y misceláneas.

B.4.1. Mercado de Factor Trabajo ${ }^{17}$

$$
\begin{aligned}
& \overline{L S}_{l a b}\left(1-U E R A T_{l a b}\right)=\sum_{a \in A} L D_{l a b, a} \\
& l a b \in L A B \\
& \frac{\frac{W L_{l a b}}{C P I}}{\frac{W L_{\text {lab }}^{0}}{C P I^{0}}}=\left(\frac{U E R A T_{\text {lab }}}{U E R A T_{\text {lab }}^{0}}\right)^{\eta_{l}} \\
& l a b \in L A B
\end{aligned}
$$

\section{B.4.2. Mercado de Factor Capital}

$$
K S=\sum_{a \in A} \overline{K D}_{a}
$$

\section{B.4.3. Cuenta Corriente del Balance de Pagos}

$\sum_{c \in C} p w e_{c} Q E_{c}+$ trnsfr $r_{\text {hhd,row }}+$ trnsfr $_{\text {gov,row }}+\sum_{\text {lab } \epsilon \text { LAB }}$ trnsfr $_{\text {lab,row }}+$ trnsf $r_{\text {cap,row }}+S A V F=\sum_{c \in C} p w m_{c} Q M_{c}$

$S A V F=\operatorname{savfb} * \overline{S A V F S C A L}$

\section{B.4.4. Equilibrio de Oferta y Demanda del bien Compuesto}

$Q Q_{c}=\sum_{a \in A} Q I N T_{c, a}+Q H_{c}+Q G_{c}+Q I N V_{c}+q d s t k_{c} \quad c \in C$

\section{B.4.5. Demanda de Inversión}

$Q I N V_{c}=q i n v b_{c} Q I N V S C A L$

$c \in C$

\section{B.4.6. Equilibrio Ahorro e inversión}

$\sum_{c \in C} P Q_{c}\left(Q I N V_{c}+q d s t k_{c}\right)+W A L R A S=M P S\left(1-t_{y}\right) Y H+S A V G+E X R S A V F$

\footnotetext{
${ }^{17}$ Notar que el supra-índice 0 refiere al valor de determinada variable en el escenario base.
} 
B.4.7. Índice de Precios al Consumidor

$\overline{C P I}=\sum_{c} P Q_{c} c w t s_{C}$

B.4.8. Índice de Precios al Productor

$D P I=\sum_{c \in C} P D_{c} d w t s_{c}$

B.4.9. Tipo de Cambio Real

$R E X R=\frac{\mathrm{EXR}}{\mathrm{DPI}}$ 


\section{Apéndice C. Descripción de la economía de Colombia en el año base}

En este apartado se describe la economía colombiana en el año base utilizado para la calibración (2016) recopilando información sobre: la estructura del PBI, la balanza de pagos, el presupuesto del gobierno, y la estructura de ingresos de las instituciones.

El ingreso de los hogares está compuesto por los ingresos factoriales del capital (47.2\%) y del trabajo (46.5\%), las transferencias del gobierno (5.31\%) y del resto del mundo (0.96\%). El ingreso del gobierno está compuesto en un $100.14 \%$ por los ingresos tributarios, ya que le presta $0.14 \%$ de sus ingresos al resto del mundo. Debido a la forma en que las transacciones con el resto del mundo son tratadas en la SAM, el ingreso de dicha institución está dado completamente por el pago a las importaciones.

Con respecto a la estructura del PBI, en la Tabla C.1 se observa que la absorción representa un $106.8 \%$ del PBI, como consecuencia de que la economía colombiana consumió más de lo que produjo, de modo que tuvo un déficit comercial de $6.8 \%$ del PBI. Respecto a los componentes de la absorción, el consumo se desagrega en privado y público, que representan $69.1 \%$ y $14.5 \%$ del PBI, respectivamente. Mientras tanto, la inversión en capital fijo es el segundo componente más importante de la absorción (22.1\% del PBI).

Por otro lado, los ingresos de divisas en la balanza de pagos representan un $21.5 \%$ del PBI. En 2016, Colombia exportó e importó por montos equivalentes a $14.7 \%$ y $21.5 \%$ del PBI, respectivamente, de modo que, como ya se ha mencionado, tuvo un déficit comercial de $6.8 \%$ del PBI. Mientras tanto, las remesas representaron $0.9 \%$ del PBI y los pagos a los factores implicaron ingresos de divisas por $0.1 \%$ del PBI. Finalmente, el saldo de la cuenta corriente evidenció un déficit del 5.8\% del PBI, igual al negativo del ahorro del resto del mundo.

En 2016, se recaudaron impuestos por un monto neto de subsidios equivalente a $18.1 \%$ del PBI, del cual un $45.63 \%$ corresponde a los impuestos a las ventas ( $8.3 \%$ del PBI), seguido de los impuestos directos que representan un $37 \%$ de dicho total (6.7\% del PIB). Notar que Colombia tiene un régimen impositivo en el que las exportaciones no están gravadas con tributo alguno ${ }^{18}$. Por el lado del gasto, en porcentaje del PBI, el consumo público es aproximadamente $14.5 \%$ y las transferencias sociales 5\%. Finalmente, gobierno se endeudó por $1.5 \%$ del PBI.

\footnotetext{
${ }^{18}$ Fuente: Ministerio de Comercio, Industria y Turismo de Colombia: http://www.mincit.gov.co/
} 
Tabla C.1. Descripción de año base. Estructura del PBI, Balanza de Pagos y Presupuesto del Gobierno. En términos nominales (billones de pesos) y en porcentaje del PBI

\begin{tabular}{lcc}
\hline & Nominal & \% PBI pm \\
\hline Componentes del PBI & & \\
Absorción & 922.246 & $106.77 \%$ \\
Consumo Privado & 596.525 & $69.06 \%$ \\
Consumo Público & 125.605 & $14.54 \%$ \\
Inversión en Capital Fijo & 191.152 & $22.13 \%$ \\
Variación de Existencias & 8.964 & $1.04 \%$ \\
Exportaciones & 127.124 & $14.72 \%$ \\
Importaciones & 185.588 & $21.49 \%$ \\
\hline PBI a precios de mercado & 863.782 & $100.00 \%$ \\
Impuestos indirectos netos & 98.768 & $11.43 \%$ \\
PBI a costo de factores & 765.014 & $88.57 \%$ \\
\hline Balanza de Pagos & & \\
Exportaciones & 127.12 & $14.72 \%$ \\
Transferencias a los Hogares & 7.88 & $0.91 \%$ \\
Transferencias al Gobierno & -0.22 & $-0.02 \%$ \\
Ingresos Factoriales & 0.91 & $0.11 \%$ \\
Ahorro del Resto del Mundo & 49.89 & $5.78 \%$ \\
\hline Ingresos Totales & 185.59 & $21.49 \%$ \\
\hline Importaciones & 185.59 & $21.49 \%$ \\
\hline Salidas Totles & 185.59 & $21.49 \%$ \\
\hline Presupuesto del Gobierno & & \\
Impuestos Directos & 57.86 & $6.70 \%$ \\
Impuestos Actividades & 22.71 & $2.63 \%$ \\
Impuestos Ventas Domésticas & 71.37 & $8.26 \%$ \\
Aranceles & 4.70 & $0.54 \%$ \\
Impuestos a las Exportaciones & & \\
Transferencias del Resto del Mundo & -0.22 & $-0.02 \%$ \\
\hline Total de Ingresos & 156.41 & $18.11 \%$ \\
\hline Gastos de Consumo & 125.61 & $14.54 \%$ \\
Transferencias Domésticas & 43.37 & $5.02 \%$ \\
Ahorro Público & -12.57 & $-1.45 \%$ \\
\hline Total de Gastos & 156.41 & $18.11 \%$ \\
\hline
\end{tabular}

Fuente: elaboración propia en base a la SAM 2016 (Cicowiez, 2019). 
Apéndice D. Resultados de las simulaciones.

Tabla D.1. Desempleo (variación en puntos porcentuales respecto a año base)

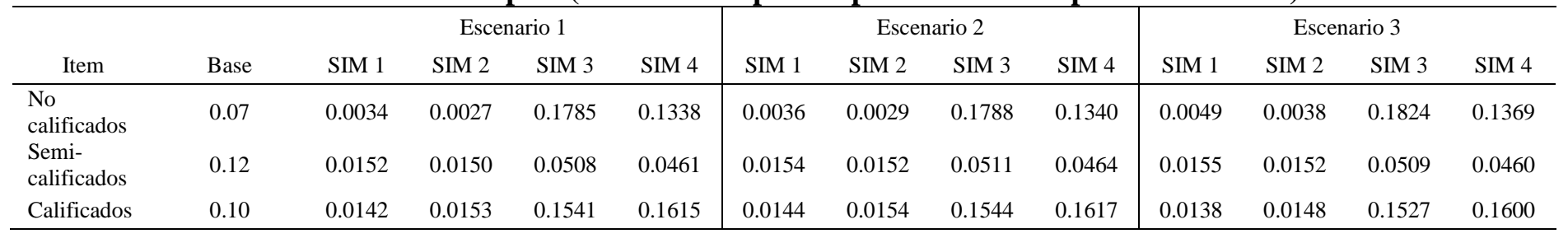

Fuente: Elaboración propia.

Notas: El escenario 1 considera un aumento de la oferta laboral de: $2.72 \%$ para no calificados, $4.34 \%$ de semicalificados y de $2.94 \%$ para calificados. El escenario 2, además del shock del escenario 1, incluye un aumento de 0.87 billones de pesos de transferencias de los hogares al resto del mundo (remesas). El escenario 3, además de los shocks anteriores, considera un aumento de gasto público de 2.33 billones de pesos y un aumento de transferencias del resto del mundo a los hogares (ayuda internacional) por 0.012 billones de pesos. El set de parámetros en cada simulación se reporta en la Tabla 6. 
Tabla D.2. Salario y Rentas Reales (cambio \% respecto a base)

\begin{tabular}{|c|c|c|c|c|c|c|c|c|c|c|c|c|c|}
\hline \multirow[b]{2}{*}{ Item } & \multirow[b]{2}{*}{ Base } & \multicolumn{4}{|c|}{ Escenario 1} & \multicolumn{4}{|c|}{ Escenario 2} & \multicolumn{4}{|c|}{ Escenario 3} \\
\hline & & SIM 1 & SIM 2 & SIM 3 & SIM 4 & SIM 1 & SIM 2 & SIM 3 & SIM 4 & SIM 1 & SIM 2 & SIM 3 & SIM 4 \\
\hline \multicolumn{14}{|l|}{ Salarios } \\
\hline No calificados & 0.95 & $-0.46 \%$ & $-0.55 \%$ & $-11.65 \%$ & $-14.49 \%$ & $-0.49 \%$ & $-0.58 \%$ & $-11.66 \%$ & $-14.50 \%$ & $-0.64 \%$ & $-0.77 \%$ & $-11.79 \%$ & $-14.68 \%$ \\
\hline Semi-calificados & 0.95 & $-1.20 \%$ & $-1.19 \%$ & $-3.52 \%$ & $-3.25 \%$ & $-1.22 \%$ & $-1.21 \%$ & $-3.54 \%$ & $-3.26 \%$ & $-1.23 \%$ & $-1.21 \%$ & $-3.53 \%$ & $-3.24 \%$ \\
\hline Calificados & 0.95 & $-1.38 \%$ & $-1.23 \%$ & $-9.18 \%$ & $-7.90 \%$ & $-1.40 \%$ & $-1.24 \%$ & $-9.19 \%$ & $-7.91 \%$ & $-1.34 \%$ & $-1.19 \%$ & $-9.13 \%$ & $-7.86 \%$ \\
\hline \multicolumn{14}{|l|}{ Remuneración al Capital } \\
\hline Agro & 0.95 & $0.74 \%$ & $0.69 \%$ & $-10.82 \%$ & $-12.28 \%$ & $0.74 \%$ & $0.70 \%$ & $-10.80 \%$ & $-12.26 \%$ & $0.54 \%$ & $0.49 \%$ & $-10.99 \%$ & $-12.47 \%$ \\
\hline Minería & 0.95 & $1.22 \%$ & $1.19 \%$ & $26.24 \%$ & $26.35 \%$ & $1.55 \%$ & $1.52 \%$ & $26.55 \%$ & $26.65 \%$ & $0.80 \%$ & $0.78 \%$ & $25.72 \%$ & $25.83 \%$ \\
\hline Alimentos & 0.95 & $1.08 \%$ & $1.08 \%$ & $42.89 \%$ & $44.43 \%$ & $1.08 \%$ & $1.09 \%$ & $42.90 \%$ & $44.45 \%$ & $1.07 \%$ & $1.09 \%$ & $42.86 \%$ & $44.43 \%$ \\
\hline Refinación de Petróleo & 0.95 & $1.35 \%$ & $1.34 \%$ & $28.02 \%$ & $28.77 \%$ & $1.55 \%$ & $1.54 \%$ & $28.19 \%$ & $28.94 \%$ & $1.13 \%$ & $1.13 \%$ & $27.77 \%$ & $28.54 \%$ \\
\hline Maquinaria & 0.95 & $1.38 \%$ & $1.35 \%$ & $36.57 \%$ & $37.20 \%$ & $1.49 \%$ & $1.46 \%$ & $36.65 \%$ & $37.28 \%$ & $0.96 \%$ & $0.94 \%$ & $36.10 \%$ & $36.74 \%$ \\
\hline Otras Manufacturas & 0.95 & $1.24 \%$ & $1.21 \%$ & $28.98 \%$ & $29.37 \%$ & $1.39 \%$ & $1.37 \%$ & $29.09 \%$ & $29.47 \%$ & $0.85 \%$ & $0.83 \%$ & $28.58 \%$ & $28.98 \%$ \\
\hline Otras Industrias & 0.95 & $1.68 \%$ & $1.61 \%$ & $20.61 \%$ & $19.27 \%$ & $1.48 \%$ & $1.41 \%$ & $20.44 \%$ & $19.10 \%$ & $0.33 \%$ & $0.27 \%$ & $19.35 \%$ & $18.02 \%$ \\
\hline Comercio y Transporte & 0.95 & $0.68 \%$ & $0.65 \%$ & $20.85 \%$ & $20.92 \%$ & $0.63 \%$ & $0.60 \%$ & $20.81 \%$ & $20.87 \%$ & $0.49 \%$ & $0.46 \%$ & $20.69 \%$ & $20.77 \%$ \\
\hline Adm. Pública & 0.95 & $-1.15 \%$ & $-1.12 \%$ & $-59.38 \%$ & $-58.82 \%$ & $-1.17 \%$ & $-1.14 \%$ & $-59.39 \%$ & $-58.82 \%$ & $-1.14 \%$ & $-1.11 \%$ & $-59.36 \%$ & $-58.79 \%$ \\
\hline Otros Servicios & 0.95 & $0.90 \%$ & $0.86 \%$ & $41.71 \%$ & $42.20 \%$ & $0.82 \%$ & $0.79 \%$ & $41.64 \%$ & $42.13 \%$ & $1.33 \%$ & $1.30 \%$ & $42.09 \%$ & $42.60 \%$ \\
\hline
\end{tabular}

Fuente: Elaboración propia.

Notas: El escenario 1 considera un aumento de la oferta laboral de: $2.72 \%$ para no calificados, $4.34 \%$ de semicalificados y de $2.94 \%$ para calificados.

El escenario 2, además del shock del escenario 1, incluye un aumento de 0.87 billones de pesos de transferencias de los hogares al resto del mundo (remesas). El escenario 3, además de los shocks anteriores, considera un aumento de gasto público de 2.33 billones de pesos y un aumento de transferencias del resto del mundo a los hogares (ayuda internacional) por 0.012 billones de pesos. El set de parámetros en cada simulación se reporta en la Tabla 6. 
Tabla D.3. Resultados Macro (Cantidades reales). Cambio \% respecto a base

\begin{tabular}{|c|c|c|c|c|c|c|c|c|c|c|c|c|c|}
\hline \multirow[b]{2}{*}{ Item } & \multirow[b]{2}{*}{ Base } & \multicolumn{4}{|c|}{ Escenario 1} & \multicolumn{4}{|c|}{ Escenario 2} & \multicolumn{4}{|c|}{ Escenario 3} \\
\hline & & SIM 1 & SIM 2 & SIM 3 & SIM 4 & SIM 1 & SIM 2 & SIM 3 & SIM 4 & SIM 1 & SIM 2 & SIM 3 & SIM 4 \\
\hline Absorción & 922.25 & $0.93 \%$ & $0.93 \%$ & $2.95 \%$ & $3.52 \%$ & $0.82 \%$ & $0.82 \%$ & $2.83 \%$ & $3.41 \%$ & $0.92 \%$ & $0.92 \%$ & $2.90 \%$ & $3.49 \%$ \\
\hline Consumo Privado & 596.53 & $0.91 \%$ & $0.90 \%$ & $5.78 \%$ & $6.32 \%$ & $0.78 \%$ & $0.77 \%$ & $5.65 \%$ & $6.19 \%$ & $0.82 \%$ & $0.82 \%$ & $5.70 \%$ & $6.26 \%$ \\
\hline oo Público & 5.61 & 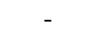 & 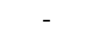 & - & - & - & - & - & - & $1.94 \%$ & $1.94 \%$ & $1.94 \%$ & $1.94 \%$ \\
\hline Formación de Capital Fijo & 191.15 & $1.66 \%$ & $1.64 \%$ & $-3.80 \%$ & $-2.73 c$ & $1.54 \%$ & $1.52 \%$ & $-3.94 \%$ & $.87 \%$ & $0.62 \%$ & $0.61 \%$ & $-5.05 \%$ & $-3.95 \%$ \\
\hline Cambio en Inventarios & 8.96 & - & - & - & - & - & - & - & - & - & - & - & - \\
\hline Exp & 127.12 & $1.15 \%$ & $1.15 \%$ & $6.15 \%$ & $7.26 \%$ & $1.43 \%$ & $1.42 \%$ & $6.43 \%$ & $7.54 \%$ & $1.01 \%$ & $1.01 \%$ & $5.96 \%$ & $7.09 \%$ \\
\hline Impo & 59 & $0.79 \%$ & $0.78 \%$ & $4.21 \%$ & $4.97 \%$ & $0.51 \%$ & $0.50 \%$ & $3.93 \%$ & $4.69 \%$ & $0.70 \%$ & $0.70 \%$ & $4.09 \%$ & $4.87 \%$ \\
\hline PBI a & 86 & $100 \%$ & $0.99 \%$ & $3.15 \%$ & $3.76 \%$ & $0.98 \%$ & $0.97 \%$ & $3.13 \%$ & $3.74 \%$ & $0.98 \%$ & $0.98 \%$ & $3.10 \%$ & $3.73 \%$ \\
\hline Impuestos Indirects & 98.77 & $0.97 \%$ & $0.96 \%$ & $2.81 \%$ & $3.34 \%$ & $0.91 \%$ & $0.90 \%$ & $2.74 \%$ & $3.27 \%$ & $0.96 \%$ & $0.96 \%$ & $2.77 \%$ & $3.31 \%$ \\
\hline PBI a costo de factores & 765.01 & $1.00 \%$ & $0.99 \%$ & $3.39 \%$ & $4.05 \%$ & $0.99 \%$ & $0.98 \%$ & $3.37 \%$ & $4.03 \%$ & $0.98 \%$ & $0.98 \%$ & $3.34 \%$ & $4.02 \%$ \\
\hline Tipo de Cambio Real & 1.000 & $0.35 \%$ & $0.34 \%$ & $-1.22 \%$ & $-1.22 \%$ & $0.55 \%$ & $0.54 \%$ & $-1.04 \%$ & $-1.04 \%$ & $0.23 \%$ & $0.22 \%$ & $-1.35 \%$ & $-1.35 \%$ \\
\hline
\end{tabular}

Fuente: Elaboración propia.

Notas: El escenario 1 considera un aumento de la oferta laboral de: $2.72 \%$ para no calificados, $4.34 \%$ de semicalificados y de $2.94 \%$ para calificados. El escenario 2, además del shock del escenario 1, incluye un aumento de 0.87 billones de pesos de transferencias de los hogares al resto del mundo (remesas). El escenario 3, además de los shocks anteriores, considera un aumento de gasto público de 2.33 billones de pesos y un aumento de transferencias del resto del mundo a los hogares (ayuda internacional) por 0.012 billones de pesos. El set de parámetros en cada simulación se reporta en la Tabla 6.

Tabla D.4. Variación Equivalente (EV)

\begin{tabular}{|c|c|c|c|c|c|c|c|c|c|c|c|c|}
\hline \multirow[b]{2}{*}{ Item } & \multicolumn{4}{|c|}{ Escenario 1} & \multicolumn{4}{|c|}{ Escenario 2} & \multicolumn{4}{|c|}{ Escenario 3} \\
\hline & SIM 1 & SIM 2 & SIM 3 & SIM 4 & SIM 1 & SIM 2 & SIM 3 & SIM 4 & SIM 1 & SIM 2 & SIM 3 & SIM 4 \\
\hline EV & 601.96 & 601.92 & 629.27 & 632.25 & 601.17 & 601.13 & 628.49 & 631.48 & 601.40 & 601.39 & 628.75 & 631.82 \\
\hline
\end{tabular}

Fuente: Elaboración propia.

Notas: El escenario 1 considera un aumento de la oferta laboral de: $2.72 \%$ para no calificados, $4.34 \%$ de semicalificados y de $2.94 \%$ para calificados. El escenario 2, además del shock del escenario 1, incluye un aumento de 0.87 billones de pesos de transferencias de los hogares al resto del mundo (remesas). El escenario 3, además de los shocks anteriores, considera un aumento de gasto público de 2.33 billones de pesos y un aumento de transferencias del resto del mundo a los hogares (ayuda internacional) por 0.012 billones de pesos. El set de parámetros en cada simulación se reporta en la Tabla 6. La EV es expresa en billones de pesos. 
Tabla D.5. Presupuesto del Gobierno (cambio \% respecto a base)

\begin{tabular}{|c|c|c|c|c|c|c|c|c|c|c|c|c|c|}
\hline Item & Base & \multicolumn{4}{|c|}{ Escenario 1} & \multicolumn{4}{|c|}{ Escenario 2} & \multicolumn{4}{|c|}{ Escenario 3} \\
\hline $\begin{array}{l}\text { Actividades } \\
\text { Impuestos a las }\end{array}$ & 22.71 & $0.96 \%$ & $0.95 \%$ & $2.48 \%$ & $2.96 \%$ & $0.93 \%$ & $0.92 \%$ & $2.45 \%$ & $2.93 \%$ & $0.97 \%$ & $0.97 \%$ & $2.49 \%$ & $2.98 \%$ \\
\hline Ventas Domésticas & 71.37 & $1.08 \%$ & $1.07 \%$ & $3.72 \%$ & $4.32 \%$ & $1.03 \%$ & $1.03 \%$ & $3.68 \%$ & $4.28 \%$ & $1.02 \%$ & $1.02 \%$ & $3.64 \%$ & $4.26 \%$ \\
\hline $\begin{array}{l}\text { Aranceles } \\
\text { Imp. a las }\end{array}$ & 4.70 & $1.29 \%$ & $1.27 \%$ & $-0.44 \%$ & $0.19 \%$ & $1.22 \%$ & $1.20 \%$ & $-0.52 \%$ & $0.11 \%$ & $0.81 \%$ & $0.80 \%$ & $-0.97 \%$ & $-0.33 \%$ \\
\hline Total de Ingresos & 156.41 & $1.00 \%$ & $1.00 \%$ & $3.97 \%$ & $4.51 \%$ & $0.93 \%$ & $0.92 \%$ & $3.90 \%$ & $4.43 \%$ & $0.93 \%$ & $0.93 \%$ & $3.89 \%$ & $4.44 \%$ \\
\hline Gastos de Consumo & 125.61 & $-0.53 \%$ & $-0.49 \%$ & $-0.95 \%$ & $-0.33 \%$ & $-0.55 \%$ & $-0.51 \%$ & $-0.97 \%$ & $-0.34 \%$ & $1.46 \%$ & $1.50 \%$ & $1.12 \%$ & $1.74 \%$ \\
\hline $\begin{array}{c}\text { Transferencias } \\
\text { Domésticas }\end{array}$ & 43.37 & $0.00 \%$ & $0.00 \%$ & $0.00 \%$ & $0.00 \%$ & $0.00 \%$ & $0.00 \%$ & $0.00 \%$ & $0.00 \%$ & $0.00 \%$ & $0.00 \%$ & $0.00 \%$ & $0.00 \%$ \\
\hline Ahorro Público & (12.57) & $17 . \overline{78 \%}$ & $17.27 \%$ & $58 . \overline{-} \%$ & $59 . \overline{43 \%}$ & $17.04 \%$ & $16.54 \%$ & $58.16 \%$ & $58.61 \%$ & $2.98 \%$ & $3.40 \%$ & $37.18 \%$ & $\begin{array}{c}- \\
37.80 \% \\
\end{array}$ \\
\hline
\end{tabular}

Fuente: Elaboración propia.

Notas: El escenario 1 considera un aumento de la oferta laboral de: $2.72 \%$ para no calificados, $4.34 \%$ de semicalificados y de $2.94 \%$ para calificados.

El escenario 2, además del shock del escenario 1, incluye un aumento de 0.87 billones de pesos de transferencias de los hogares al resto del mundo (remesas). El escenario 3, además de los shocks anteriores, considera un aumento de gasto público de 2.33 billones de pesos y un aumento de transferencias del resto del mundo a los hogares (ayuda internacional) por 0.012 billones de pesos. El set de parámetros en cada simulación se reporta en la Tabla 6. 
Tabla D.6. Producto Real por sector (cambio \% respecto a la base)

\begin{tabular}{|c|c|c|c|c|c|c|c|c|c|c|c|c|c|}
\hline \multirow[b]{2}{*}{ Item } & \multirow[b]{2}{*}{ Base } & \multicolumn{4}{|c|}{ Escenario 1} & \multicolumn{4}{|c|}{ Escenario 2} & \multicolumn{4}{|c|}{ Escenario 3} \\
\hline & & SIM 1 & SIM 2 & SIM 3 & SIM 4 & SIM 1 & SIM 2 & SIM 3 & SIM 4 & SIM 1 & SIM 2 & SIM 3 & SIM 4 \\
\hline Agro & 82.2 & $1.19 \%$ & $1.22 \%$ & $33.27 \%$ & $37.00 \%$ & $1.22 \%$ & $1.25 \%$ & $33.35 \%$ & $37.09 \%$ & $1.16 \%$ & $1.21 \%$ & $33.19 \%$ & $37.00 \%$ \\
\hline Minería & 64.9 & $0.64 \%$ & $0.63 \%$ & $-5.07 \%$ & $-4.83 \%$ & $0.74 \%$ & $0.73 \%$ & $-4.99 \%$ & $-4.76 \%$ & $0.54 \%$ & $0.54 \%$ & $-5.17 \%$ & $-4.93 \%$ \\
\hline Alimentos & 112.0 & $1.04 \%$ & $1.04 \%$ & $15.58 \%$ & $16.88 \%$ & $1.05 \%$ & $1.06 \%$ & $15.61 \%$ & $16.91 \%$ & $1.07 \%$ & $1.09 \%$ & $15.57 \%$ & $16.90 \%$ \\
\hline Refinación de Petróleo & 45.9 & $0.59 \%$ & $0.59 \%$ & $-0.37 \%$ & $-0.20 \%$ & $0.65 \%$ & $0.64 \%$ & $-0.33 \%$ & $-0.16 \%$ & $0.55 \%$ & $0.55 \%$ & $-0.43 \%$ & $-0.25 \%$ \\
\hline Maquinaria & 18.8 & $1.22 \%$ & $1.20 \%$ & $7.27 \%$ & $7.48 \%$ & $1.28 \%$ & $1.27 \%$ & $7.34 \%$ & $7.55 \%$ & $1.04 \%$ & $1.03 \%$ & $6.95 \%$ & $7.17 \%$ \\
\hline Otras Manufacturas & 154.0 & $1.15 \%$ & $1.14 \%$ & $3.48 \%$ & $4.00 \%$ & $1.23 \%$ & $1.22 \%$ & $3.56 \%$ & $4.08 \%$ & $0.98 \%$ & $0.98 \%$ & $3.23 \%$ & $3.76 \%$ \\
\hline Otras Industrias & 194.2 & $1.44 \%$ & $1.43 \%$ & $-2.29 \%$ & $-1.32 \%$ & $1.34 \%$ & $1.33 \%$ & $-2.41 \%$ & $-1.44 \%$ & $0.74 \%$ & $0.74 \%$ & $-3.15 \%$ & $-2.16 \%$ \\
\hline Comercio y Transporte & 203.8 & $1.13 \%$ & $1.12 \%$ & $6.55 \%$ & $7.26 \%$ & $1.11 \%$ & $1.11 \%$ & $6.53 \%$ & $7.23 \%$ & $1.06 \%$ & $1.06 \%$ & $6.42 \%$ & $7.15 \%$ \\
\hline Adm. Pública & 83.6 & $0.02 \%$ & $0.02 \%$ & $0.14 \%$ & $0.13 \%$ & $0.02 \%$ & $0.02 \%$ & $0.14 \%$ & $0.13 \%$ & $0.04 \%$ & $0.04 \%$ & $0.16 \%$ & $0.15 \%$ \\
\hline Otros Servicios & 584.3 & $1.00 \%$ & $0.98 \%$ & $-0.70 \%$ & $-0.46 \%$ & $0.97 \%$ & $0.95 \%$ & $-0.74 \%$ & $-0.50 \%$ & $1.15 \%$ & $1.14 \%$ & $-0.54 \%$ & $-0.29 \%$ \\
\hline Total & 1543.7 & $1.02 \%$ & $1.01 \%$ & $3.43 \%$ & $4.10 \%$ & $1.01 \%$ & $1.00 \%$ & $3.42 \%$ & $4.09 \%$ & $0.96 \%$ & $0.96 \%$ & $3.33 \%$ & $4.02 \%$ \\
\hline
\end{tabular}

Fuente: Elaboración propia.

Notas: El escenario 1 considera un aumento de la oferta laboral de: $2.72 \%$ para no calificados, $4.34 \%$ de semicalificados y de $2.94 \%$ para calificados. El escenario 2, además del shock del escenario 1, incluye un aumento de 0.87 billones de pesos de transferencias de los hogares al resto del mundo (remesas). El escenario 3, además de los shocks anteriores, considera un aumento de gasto público de 2.33 billones de pesos y un aumento de transferencias del resto del mundo a los hogares (ayuda internacional) por 0.012 billones de pesos. El set de parámetros en cada simulación se reporta en la Tabla 6. 
Tabla D.7. Exportaciones Reales (cambio \% respecto a base)

\begin{tabular}{|c|c|c|c|c|c|c|c|c|c|c|c|c|c|}
\hline \multirow[b]{2}{*}{ Item } & \multirow[b]{2}{*}{ Base } & \multicolumn{4}{|c|}{ Escenario 1} & \multicolumn{4}{|c|}{ Escenario 2} & \multicolumn{4}{|c|}{ Escenario 3} \\
\hline & & SIM 1 & SIM 2 & SIM 3 & SIM 4 & SIM 1 & SIM 2 & SIM 3 & SIM 4 & SIM 1 & SIM 2 & SIM 3 & SIM 4 \\
\hline Agro & 7.9 & $1.94 \%$ & $2.04 \%$ & $100.25 \%$ & $113.12 \%$ & $2.35 \%$ & $2.45 \%$ & $100.99 \%$ & $113.93 \%$ & $1.82 \%$ & $1.97 \%$ & $99.90 \%$ & $113.04 \%$ \\
\hline Minería & 41.7 & $0.46 \%$ & $0.45 \%$ & $-7.57 \%$ & $-7.48 \%$ & $0.60 \%$ & $0.59 \%$ & $-7.46 \%$ & $-7.38 \%$ & $0.45 \%$ & $0.44 \%$ & $-7.54 \%$ & $-7.46 \%$ \\
\hline Alimentos & 13.0 & $1.59 \%$ & $1.61 \%$ & $27.60 \%$ & $29.92 \%$ & $1.97 \%$ & $2.00 \%$ & $28.06 \%$ & $30.38 \%$ & $1.41 \%$ & $1.45 \%$ & $27.28 \%$ & $29.63 \%$ \\
\hline Refinación de Petróleo & 8.5 & $0.28 \%$ & $0.27 \%$ & $-6.00 \%$ & $-6.33 \%$ & $0.47 \%$ & $0.46 \%$ & $-5.83 \%$ & $-6.16 \%$ & $0.26 \%$ & $0.25 \%$ & $-6.01 \%$ & $-6.35 \%$ \\
\hline Maquinaria & 5.1 & $1.18 \%$ & $1.16 \%$ & $11.80 \%$ & $11.60 \%$ & $1.37 \%$ & $1.35 \%$ & $12.02 \%$ & $11.82 \%$ & $1.25 \%$ & $1.24 \%$ & $11.74 \%$ & $11.53 \%$ \\
\hline Comercio y Transporte & 7.8 & $2.02 \%$ & $2.02 \%$ & $10.76 \%$ & $11.50 \%$ & $2.39 \%$ & $2.39 \%$ & $11.11 \%$ & $11.85 \%$ & $1.76 \%$ & $1.78 \%$ & $10.37 \%$ & $11.13 \%$ \\
\hline Adm. Pública & 0.0 & $2.29 \%$ & $2.16 \%$ & $3.89 \%$ & $2.00 \%$ & $2.70 \%$ & $2.56 \%$ & $4.25 \%$ & $2.35 \%$ & $1.88 \%$ & $1.75 \%$ & $3.41 \%$ & $1.54 \%$ \\
\hline Otros Servicios & 13.7 & $1.93 \%$ & $1.87 \%$ & $-14.97 \%$ & $-15.33 \%$ & $2.35 \%$ & $2.28 \%$ & $-14.67 \%$ & $-15.04 \%$ & $1.38 \%$ & $1.33 \%$ & $-15.39 \%$ & $-15.74 \%$ \\
\hline Total & 127.1 & $1.15 \%$ & $1.15 \%$ & $6.15 \%$ & $7.26 \%$ & $1.43 \%$ & $1.42 \%$ & $6.43 \%$ & $7.54 \%$ & $1.01 \%$ & $1.01 \%$ & $5.96 \%$ & $7.09 \%$ \\
\hline
\end{tabular}

Fuente: Elaboración propia.

Notas: El escenario 1 considera un aumento de la oferta laboral de: $2.72 \%$ para no calificados, $4.34 \%$ de semicalificados y de $2.94 \%$ para calificados. El escenario 2, además del shock del escenario 1, incluye un aumento de 0.87 billones de pesos de transferencias de los hogares al resto del mundo (remesas). El escenario 3, además de los shocks anteriores, considera un aumento de gasto público de 2.33 billones de pesos y un aumento de transferencias del resto del mundo a los hogares (ayuda internacional) por 0.012 billones de pesos. El set de parámetros en cada simulación se reporta en la Tabla 6. 
Tabla D.8. Importaciones Reales (cambio \% respecto a base)

\begin{tabular}{|c|c|c|c|c|c|c|c|c|c|c|c|c|c|}
\hline \multirow[b]{2}{*}{ Item } & \multirow[b]{2}{*}{ Base } & \multicolumn{4}{|c|}{ Escenario 1} & \multicolumn{4}{|c|}{ Escenario 2} & \multicolumn{4}{|c|}{ Escenario 3} \\
\hline & & SIM 1 & SIM 2 & SIM 3 & SIM 4 & SIM 1 & SIM 2 & SIM 3 & SIM 4 & SIM 1 & SIM 2 & SIM 3 & SIM 4 \\
\hline Agro & 7.0 & $0.27 \%$ & $0.22 \%$ & $21.74 \%$ & $23.49 \%$ & $0.14 \%$ & $0.20 \%$ & $22.05 \%$ & $23.79 \%$ & $0.35 \%$ & $0.29 \%$ & $21.67 \%$ & $23.46 \%$ \\
\hline Alimentos & 13.5 & $0.34 \%$ & $0.33 \%$ & $1.78 \%$ & $2.02 \%$ & $\stackrel{-}{0.11 \%}$ & $0.12 \%$ & $1.36 \%$ & $1.60 \%$ & $0.64 \%$ & $0.64 \%$ & $2.11 \%$ & $2.35 \%$ \\
\hline Refinación de Petróleo & 12.5 & $1.06 \%$ & $1.05 \%$ & $8.27 \%$ & $9.26 \%$ & $0.91 \%$ & $0.91 \%$ & $8.12 \%$ & $9.11 \%$ & $0.98 \%$ & $0.98 \%$ & $8.15 \%$ & $9.16 \%$ \\
\hline Maquinaria & 52.1 & $1.29 \%$ & $1.28 \%$ & $-0.32 \%$ & $0.55 \%$ & $1.13 \%$ & $1.12 \%$ & $-0.49 \%$ & $0.39 \%$ & $0.68 \%$ & $0.68 \%$ & $-1.04 \%$ & $-0.14 \%$ \\
\hline Comercio y Transporte & 6.8 & $0.17 \%$ & $0.17 \%$ & $2.18 \%$ & $2.84 \%$ & $\begin{array}{c}- \\
0.26 \%\end{array}$ & $\begin{array}{c}- \\
0.26 \%\end{array}$ & $1.78 \%$ & $2.45 \%$ & $0.30 \%$ & $0.29 \%$ & $2.32 \%$ & $3.00 \%$ \\
\hline Adm. Pública & 0.0 & $\begin{array}{c}- \\
2.19 \%\end{array}$ & $\begin{array}{c}- \\
2.07 \%\end{array}$ & $-3.48 \%$ & $-1.70 \%$ & $\begin{array}{c}- \\
2.58 \%\end{array}$ & $2 . \overline{-}$ & $-3.82 \%$ & $-2.04 \%$ & $\begin{array}{c}- \\
1.76 \%\end{array}$ & $\begin{array}{c}- \\
1.64 \%\end{array}$ & $-3.00 \%$ & $-1.22 \%$ \\
\hline Otros Servicios & 24.8 & $0.02 \%$ & $0.05 \%$ & $16.72 \%$ & $17.82 \%$ & $\begin{array}{c}- \\
0.46 \%\end{array}$ & $\begin{array}{c}- \\
0.43 \% \\
\end{array}$ & $16.21 \%$ & $17.32 \%$ & $0.91 \%$ & $0.94 \%$ & $17.71 \%$ & $18.83 \%$ \\
\hline
\end{tabular}

Fuente: Elaboración propia.

Notas: El escenario 1 considera un aumento de la oferta laboral de: $2.72 \%$ para no calificados, $4.34 \%$ de semicalificados y de $2.94 \%$ para calificados. El escenario 2, además del shock del escenario 1, incluye un aumento de 0.87 billones de pesos de transferencias de los hogares al resto del mundo (remesas). El escenario 3, además de los shocks anteriores, considera un aumento de gasto público de 2.33 billones de pesos y un aumento de transferencias del resto del mundo a los hogares (ayuda internacional) por 0.012 billones de pesos. El set de parámetros en cada simulación se reporta en la Tabla 6. 
Tabla D.9. Ventas Domésticas Reales (cambio \% respecto a base)

\begin{tabular}{|c|c|c|c|c|c|c|c|c|c|c|c|c|c|}
\hline \multirow[b]{2}{*}{ Item } & \multirow[b]{2}{*}{ Base } & \multicolumn{4}{|c|}{ Escenario 1} & \multicolumn{4}{|c|}{ Escenario 2} & \multicolumn{4}{|c|}{ Escenario 3} \\
\hline & & SIM 1 & SIM 2 & SIM 3 & SIM 4 & SIM 1 & $\operatorname{SIM} 2$ & $\operatorname{SIM} 3$ & SIM 4 & SIM 1 & SIM 2 & SIM 3 & SIM 4 \\
\hline Agro & 74.3 & $1.10 \%$ & $1.13 \%$ & $25.18 \%$ & $27.70 \%$ & $1.09 \%$ & $1.12 \%$ & $25.17 \%$ & $27.69 \%$ & $1.09 \%$ & $1.12 \%$ & $25.13 \%$ & $27.70 \%$ \\
\hline Alimentos & 99.1 & $0.96 \%$ & $0.97 \%$ & $13.96 \%$ & $15.12 \%$ & $0.93 \%$ & $0.93 \%$ & $13.93 \%$ & $15.09 \%$ & $1.02 \%$ & $1.04 \%$ & $14.00 \%$ & $15.19 \%$ \\
\hline Refinación de Petróleo & 37.4 & $0.67 \%$ & $0.66 \%$ & $0.89 \%$ & $1.17 \%$ & $0.69 \%$ & $0.68 \%$ & $0.90 \%$ & $1.18 \%$ & $0.62 \%$ & $0.62 \%$ & $0.82 \%$ & $1.11 \%$ \\
\hline Maquinaria & 13.7 & $1.23 \%$ & $1.22 \%$ & $5.57 \%$ & $5.93 \%$ & $1.25 \%$ & $1.24 \%$ & $5.58 \%$ & $5.95 \%$ & $0.97 \%$ & $0.96 \%$ & $5.16 \%$ & $5.53 \%$ \\
\hline Otras Industrias & 194.2 & $1.44 \%$ & $1.43 \%$ & $-2.29 \%$ & $-1.32 \%$ & $1.34 \%$ & $1.33 \%$ & $-2.41 \%$ & $-1.44 \%$ & $0.74 \%$ & $0.74 \%$ & $-3.15 \%$ & $-2.16 \%$ \\
\hline Comercio y Transporte & 196.0 & $1.09 \%$ & $1.09 \%$ & $6.38 \%$ & $7.09 \%$ & $1.06 \%$ & $1.06 \%$ & $6.34 \%$ & $7.05 \%$ & $1.03 \%$ & $1.03 \%$ & $6.27 \%$ & $6.99 \%$ \\
\hline Adm. Pública & 83.6 & $0.02 \%$ & $0.02 \%$ & $0.14 \%$ & $0.13 \%$ & $0.02 \%$ & $0.02 \%$ & $0.14 \%$ & $0.13 \%$ & $0.04 \%$ & $0.04 \%$ & $0.16 \%$ & $0.15 \%$ \\
\hline Otros Servicios & 570.6 & $0.97 \%$ & $0.96 \%$ & $-0.38 \%$ & $-0.12 \%$ & $0.94 \%$ & $0.92 \%$ & $-0.42 \%$ & $-0.16 \%$ & $1.14 \%$ & $1.13 \%$ & $-0.20 \%$ & $0.07 \%$ \\
\hline Total & 1416.6 & $1.01 \%$ & $1.00 \%$ & $3.13 \%$ & $3.74 \%$ & $0.98 \%$ & $0.97 \%$ & $3.09 \%$ & $3.71 \%$ & $0.95 \%$ & $0.95 \%$ & $3.03 \%$ & $3.66 \%$ \\
\hline
\end{tabular}

Fuente: Elaboración propia.

Notas: El escenario 1 considera un aumento de la oferta laboral de: $2.72 \%$ para no calificados, $4.34 \%$ de semicalificados y de $2.94 \%$ para calificados.

El escenario 2, además del shock del escenario 1, incluye un aumento de 0.87 billones de pesos de transferencias de los hogares al resto del mundo (remesas). El escenario 3, además de los shocks anteriores, considera un aumento de gasto público de 2.33 billones de pesos y un aumento de transferencias del resto del mundo a los hogares (ayuda internacional) por 0.012 billones de pesos. El set de parámetros en cada simulación se reporta en la Tabla 6. 